\title{
Competing Manufacturers in a Retail Supply Chain: On Contractual Form and Coordination
}

\author{
Gérard P. Cachon \\ The Wharton School, University of Pennsylvania, Philadelphia, Pennsylvania 19104, \\ cachon@wharton.upenn.edu \\ A. Gürhan Kök \\ Fuqua School of Business, Duke University, Durham, North Carolina 27708, \\ gurhan.kok@duke.edu
}

\begin{abstract}
T $\mathrm{t}$ is common for a retailer to sell products from competing manufacturers. How then should the firms manage their contract negotiations? The supply chain coordination literature focuses either on a single manufacturer selling to a single retailer or one manufacturer selling to many (possibly competing) retailers. We find that some key conclusions from those market structures do not apply in our setting, where multiple manufacturers sell through a single retailer. We allow the manufacturers to compete for the retailer's business using one of three types of contracts: a wholesale-price contract, a quantity-discount contract, or a two-part tariff. It is well known that the latter two, more sophisticated contracts enable the manufacturer to coordinate the supply chain, thereby maximizing the profits available to the firms. More importantly, they allow the manufacturer to extract rents from the retailer, in theory allowing the manufacturer to leave the retailer with only her reservation profit. However, we show that in our market structure these two sophisticated contracts force the manufacturers to compete more aggressively relative to when they only offer wholesale-price contracts, and this may leave them worse off and the retailer substantially better off. In other words, although in a serial supply chain a retailer may have just cause to fear quantity discounts and two-part tariffs, a retailer may actually prefer those contracts when offered by competing manufacturers. We conclude that the properties a contractual form exhibits in a one-manufacturer supply chain may not carry over to the realistic setting in which multiple manufacturers must compete to sell their goods through the same retailer.
\end{abstract}

Key words: contracting; competition; retailing; wholesale-price contract; quantity discount; two-part tariff History: Received November 25, 2007; accepted November 6, 2009, by Ananth Iyer, operations and supply chain management. Published online in Articles in Advance January 29, 2010.

\section{Introduction}

The literature on supply chain coordination has studied several contractual forms in settings with a single manufacturer and one or more retailers. One of the key results from this literature is that wholesaleprice contracts lead to suboptimal decisions for the supply chain (i.e., double marginalization), and more sophisticated contracts (like quantity discounts or two-part tariffs) can be employed by a manufacturer to achieve both supply chain coordination (i.e., maximize the supply chain's profit) and rent extraction (i.e., the ability to allocate a high share of the profits to the manufacturer). Thus, they are viewed to work to the advantage of the manufacturer and to the possible disadvantage of the retailer (coordination is good for the retailer but rent extraction is bad). Our objective is to test these conclusions in a setting in which multiple manufacturers compete to sell their products through a single retailer.

In our model, two manufacturers simultaneously offer to the retailer one of three types of contracts: a wholesale-price contract, a quantity-discount contract (i.e., a decreasing per-unit price in the quantity purchased), or a two-part tariff (i.e., a per-unit price and a fixed fee). We refer to the latter two as "sophisticated" contracts. The retailer determines the products' demand rates (by choosing a price for each of them) to maximize her total profit given the offered contracts and her inventory costs, which may exhibit economies of scale. This model represents a common supply chain structure, as many manufacturers sell their products through retailers that also sell similar products from other manufacturers. A typical example is Procter \& Gamble's Crest toothpaste versus Colgate-Palmolive's Colgate toothpaste at a supermarket.

To understand how competition among multiple manufacturers influences contracting with a retailer, consider an illustrative setting in which manufacturers A and B sell their products to a single retailer, as depicted in Figure 1. Focus on the supply chain formed by manufacturer $\mathrm{A}$ and the retailer. Without 
Figure 1 Four Profit Scenarios Holding Manufacturer B's Contract Fixed

\begin{tabular}{|c|c|c|c|c|}
\hline \multirow[b]{2}{*}{ Scenario } & \multirow{2}{*}{$\begin{array}{c}\text { Manufacturer } \\
\text { A } \\
\end{array}$} & \multicolumn{2}{|c|}{ Retailer } & \multirow{2}{*}{$\begin{array}{c}\text { Manufacturer } \\
\text { B }\end{array}$} \\
\hline & & A & B & \\
\hline $\begin{array}{l}\text { Product } \mathrm{A} \text { is not in } \\
\text { the assortment }\end{array}$ & 0 & 0 & 奋 & $\stackrel{8}{\boxplus}$ \\
\hline $\begin{array}{l}\text { Retailer's maximum } \\
\text { profit with A in the } \\
\text { assortment }\end{array}$ & 0 & \# & $\begin{array}{l}5 \\
\text { 日 }\end{array}$ & $\begin{array}{l}3 \\
日\end{array}$ \\
\hline $\begin{array}{l}\text { An unacceptable } \\
\text { allocation of profit for } \\
\text { the retailer }\end{array}$ & $\begin{array}{l}7 \\
\text { 由 }\end{array}$ & $\stackrel{9}{\boxplus}$ & $\begin{array}{l}2 \\
\text { 日 }\end{array}$ & $\begin{array}{l}1 \\
\square\end{array}$ \\
\hline $\begin{array}{l}\text { An acceptable } \\
\text { allocation of profit for } \\
\text { the retailer }\end{array}$ & $\stackrel{6}{日}$ & $\boxplus$ & 每 & $\begin{array}{l}3 \\
日\end{array}$ \\
\hline
\end{tabular}

Notes. Each box represents a unit of profit. Product A's incremental value is 6 because that is the retailer's maximum increase in her profit by adding product $A$ to the assortment. Scenario 3 is unacceptable to the retailer because the retailer prefers Scenario 1 in which product $A$ is not included in the assortment. In Scenario 4, manufacturer A earns his incremental profit, and the retailer is indifferent between including $A$ in the assortment or not.

product $\mathrm{A}$ in the assortment, say the retailer earns 12 units of profit given manufacturer B's contract (Scenario 1). Hence, the retailer's reservation profit is 12 when considering A's contract offer; that is, the retailer accepts A's offer and add A's product to the assortment only if the retailer can earn a profit of at least 12 . The supply chain is said to be "coordinated" when their combined profit is maximized. This occurs when A sells his product at cost to the retailer-in that case, the retailer earns all of the supply chain's profit and so chooses prices to maximize it. We refer to this profit as the maximum profit, and in this example, say, it is 18 (Scenario 2). Finally, define product A's incremental profit as the difference between the supply chain's maximum profit and the retailer's reservation profit, which in this example is $6(18-12)$.

A product's incremental profit is a useful construct because, among all possible contracts, it is the upper bound on how much a manufacturer can earn. To explain, if A were to offer a contract such that A earned more than his incremental profit, then it must be that the retailer is earning less than her reservation profit, and so she will reject the contract (Scenario 3). Thus, A's objective is to try to earn as much of his incremental profit as possible. To earn all of the incremental profit requires supply chain coordination and substantial rent extraction (i.e., A earns 6 units of profit, leaving the retailer with her reservation profit of 12), as in Scenario 4 . This is true whether $\mathrm{A}$ is a monopolist or is competing with another manufacturer. For example, a wholesale-price contract does not allow a monopolist manufacturer to earn his incremental profit (because it fails on coordination and has limited rent extraction), but the manufacturer can achieve this with a properly designed sophisticated contract, hence the advantage of sophisticated contracts for a monopolist manufacturer. In fact, the same is true even when the manufacturers must compete-holding the other firm's contract offer fixed, the sophisticated contracts allow a manufacturer to capture a large fraction (possibly all) of its incremental profit. In other words, holding B's contract offer fixed, A prefers a well-designed sophisticated contract over the wholesale-price contract.

So what changes in the contracting process when manufacturers compete? The answer is that a manufacturer's incremental profit is exogenously determined when there is no competition and endogenously determined when there is competition. Returning to our example, A's incremental profit is 6 for a given contract offered by $B$. If $B$ were to offer a different contract, then A's incremental profit could be different (possibly more, possibly less). Furthermore, we will show that A's incremental profit declines as B uses a more sophisticated contract (and vice versa), and it declines substantially when the products are close substitutes or if there are substantial economies of scale in inventory costs, or both. (This holds because adding product A to the retailer's assortment increases the retailer's profit more when manufacturer B offers a contract that does not maximize the total profit from product B.) If they both use sophisticated contracts, they will both be able to capture a large portion of their incremental profits (which is why they prefer these contracts holding the other firm's contract offer fixed), but if the products are close substitutes, their incremental profits will be "small." In contrast, if they both offer wholesale-price contracts, then they will both be able to capture only a modest portion of their incremental profits, but their incremental profits will be "large." In short, it can be better to have a piece of a large pie (with wholesale-price contracts) than to have all of a small pie (with the sophisticated contracts). It follows that when the manufacturers sell close substitutes through a common retailer, sophisticated contracts can work to their disadvantage, which is in sharp contrast to the results with a single manufacturer. Put another way, although the existing supply chain coordination literature suggest that a retailer should be wary of a manufacturer offering sophisticated contracts (because this could lead the retailer to earn only her reservation profit), our results with competing manufacturers suggest that the retailer may prefer that they offer sophisticated contracts (because the supply chain is coordinated but the manufacturers have small incremental values).

The rest of this paper is organized as follows. Section 2 reviews the relevant literature. Section 3 describes the model. Section 4 presents our analysis of the retailer's problem, $\S 5$ the analysis and comparison 
of the wholesale-price, quantity-discount, and twopart tariff games, and $\S 6$ the numerical study. Section 7 concludes this paper. All proofs are presented in the appendix.

\section{Relation to the Literature}

The present paper is foremost a commentary on the supply chain coordination literature. See Cachon (2003) for a review of this literature. As already discussed, this literature focuses on either relationships with bilateral monopoly or models with one manufacturer and multiple retailers. Wholesale-price contracts are nearly always found to be inefficient, and more sophisticated contracts can be used to eliminate that inefficiency and reallocate rents arbitrarily between the parties in the supply chain. ${ }^{1}$ There is an extensive literature on supply chain coordination with quantitydiscount contracts and price-dependent demand (e.g., Jeuland and Shugan 1983, Moorthy 1987, Ingene and Perry 1995) and on lot-size coordination with fixed demand (e.g., Monahan 1984, Corbett and de Groote 2000), but they consider only one manufacturer.

Choi (1991), Trivedi (1998), Lee and Staelin (1997), and Martinez de Albeniz and Roels (2007) study systems with multiple manufacturers and a common retailer, but they only consider wholesale-price contracts. The literature on common agency (Bernheim and Whinston 1985, 1986) and vertical separation in economics is also relevant, because they study models with multiple manufacturers and retailers that could sell more than one product. Mathewson and Winter (1987) explore whether or not exclusive dealing arrangements lead to foreclosure of rivals and the implications for antitrust laws considering only wholesale-price contracts. Bernheim and Whinston (1998) and O'Brien and Shaffer (1993, 1997) explore similar issues with two-part tariffs. Other variations of the basic model include manufacturers that invest in the retailers to reduce the marginal selling cost (Besanko and Perry 1994) and manufacturers that assign exclusive territories to retailers to reduce competition (Rey and Stiglitz 1995). The general result is that the manufacturers may prefer exclusive dealing due to reduced competition at the retailer level even though societal welfare and industry profits may be higher with common agency. This is essentially a comparison of different supply chain structures, whereas we are concerned with the effect of different contract

\footnotetext{
${ }^{1}$ A wholesale-price contract can maximize profits in a system with one manufacturer and multiple quantity competing retailers. However, it provides only one allocation of the system's rents, and it is not even the manufacturer's optimal wholesale price (see Cachon and Lariviere 2005). If retailers compete on price and quantity, then the wholesale price no longer guarantees coordination (see Bernstein and Federgruen 2003, 2005).
}

types in a given supply chain structure. Also related to two-part tariffs, there is a literature on slotting fees (which are essentially two-part tariffs with negative payments to the manufacturer; see, for example, Marx and Shaffer 2010). Kuksov and Pazgal (2007) show that slotting fees do not occur in a setting with simultaneous manufacturer competition and a single retailer, and the same result applies in our model. The literature on strategic decentralization in marketing is highly relevant. McGuire and Staelin (1983) study two competing supply chains under two structural forms: in each supply chain either the manufacturer sells to a dedicated retailer via a wholesale-price contract or the manufacturer vertically integrates into retailing. In either structure, the products of the two manufacturers are sold to consumers from different firms, whereas in our model the manufacturers' products are sold through a single independent retailer. Nevertheless, there are some similarities in our results. McGuire and Staelin (1983) find that the manufacturers may prefer to sell via wholesale-price contracts, despite the fact that they do not coordinate the channel nor allow the manufacturer to extract all rents, because they dampen retail competition between the two products relative to the vertically integrated structure. In our model, competition to consumers is held constant, because we have a single retailer, so what changes is that the retailer's reservation profit now depends on the contract offers by the manufacturers, enabling the retailer to gain more of the supply chain profits due to the manufacturers' competition. Coughlan (1985) confirms the McGuire and Staelin (1983) findings in an empirical study of the international semiconductor industry. In the context of the McGuire and Staelin (1983) model, Moorthy (1988) provides conditions on the characteristics of the game and the demand function for decentralization to be an equilibrium strategy, and Bonanno and Vickers (1988) show that decentralization is always the equilibrium when both manufacturers employ two-part tariffs. In a different context with strategic consumers timing their purchase of a product, Desai et al. (2004) and Arya and Mittendorf (2006) consider a monopolist manufacturer and show that decentralization through wholesale-price contracts can yield higher profits for the channel.

\section{The Model}

There are two products in the market supplied by two different manufacturers. The products are partial substitutes and are sold through a common retailer. In the first stage of the game, the manufacturers simultaneously announce the payment schemes for their products, i.e., their contract offers. In the second stage, the retailer chooses prices, which determine the products' 
demand rates, to maximize her profit. In addition to the payments to the manufacturer, the retailer incurs operating costs that depend on the average volume sold of each product. The manufacturers incur constant marginal production costs.

The retailer faces price sensitive customers. The revenue from product $i$ is

$$
R_{i}(d)=p_{i}(d) d_{i}
$$

where $d_{i}$ is the demand rate of product $i, d$ is the pair of demand rates, and the inverse demand function is

$$
p_{i}(d)=\theta_{i}-\beta_{i} d_{i}-\gamma_{i} d_{j} \text { and } \beta_{i}>\gamma_{j}>0 \text { for all } i, j .
$$

We elect to work with the inverse demand function for expositional simplicity. The formulation with the demand function is equivalent to the above.

Let $G_{i}\left(d_{i}\right)$ be the retailer's inventory related operational costs of product $i$,

$$
G_{i}\left(d_{i}\right)=K_{i} d_{i}^{\lambda}, \quad K_{i} \geq 0,0<\lambda<1,
$$

where $K_{i}$ and $\lambda$ are exogenous constants. This functional form, which exhibits economies of scale, is a general representation of the inventory costs that arise in common inventory replenishment models such as a base-stock model $^{2}$ or an economic order quantity (EOQ) model. ${ }^{3}$

Let $\pi_{i}$ denote the retailer's profit from product $i$ and $\pi=\pi_{i}+\pi_{j}$, the retailer's total profit. It follows that

$$
\pi_{i}=R_{i}(d)-G_{i}\left(d_{i}\right)-T_{i}\left(d_{i}\right),
$$

and $T_{i}\left(d_{i}\right)$ is the payment made to the manufacturer based on the retailer's demand rate and their agreedupon contract. ${ }^{4}$ Manufacturer $i^{\prime}$ 's profit is

$$
\Pi_{i}=T_{i}\left(d_{i}\right)-c_{i} d_{i}
$$

where $c_{i}$ is the manufacturer's cost per unit.

\footnotetext{
${ }^{2}$ In a periodic review model where demand follows a Normal distribution with mean $d_{i}$ and standard deviation $\sigma_{i} d_{i}^{\lambda}$, the total inventory related costs with the optimal base-stock level is given by $(b+h) \phi\left(z^{*}\right) \sigma_{i} d_{i}^{\lambda}$, where $b$ is the backlog penalty per unit and $h$ is the inventory holding cost per period. Defining $K_{i}=(b+h) \phi\left(z^{*}\right) \sigma_{i}$ leads to the $G_{i}$ function.

${ }^{3}$ In the EOQ model, the retailer incurs a fixed cost $k_{i}$ per order and a holding cost $h_{i}$ per unit of inventory held for one period. The well-known EOQ formula suggests ordering every $\sqrt{2 k_{i} / h_{i} d_{i}}$ periods. The resulting optimal total inventory and ordering cost is given by $\sqrt{2 k_{i} d_{i} h_{i}}$. Defining $K_{i}=\sqrt{2 k_{i} h_{i}}$ leads to the $G_{i}$ function with $\lambda=1 / 2$.

${ }^{4}$ The retailer's payment $T_{i}\left(d_{i}\right)$ to a manufacturer can be interpreted as a yearly (average) payment based on yearly (average) volume. Many manufacturer-retailer purchasing contracts are based on the yearly volume rather than on the volume of individual shipments.
}

We focus on three different types of contracts: wholesale-price contracts, quantity-discount contracts, and two-part tariffs. In the first stage, the manufacturers' strategy set includes one or more of these contractual forms. For expositional clarity, we begin with a limited strategy space (e.g., just wholesaleprice contracts, or just quantity-discount contracts, etc.) and then later consider a broader strategy space.

With a wholesale-price contract, the payment function is

$$
T_{i}\left(d_{i}\right)=w_{i} d_{i},
$$

where $w_{i}$ is the wholesale price chosen by manufacturer $i$. Wholesale-price contracts are common in practice and serve as a theoretical benchmark.

Quantity discounts are common in many industries (see Munson and Rosenblatt 1998 for a field study). We consider the following family of quantity discounts:

$$
T_{i}\left(d_{i}\right)=\left\{\begin{array}{c}
w_{i} d_{i}-v_{i} d_{i}^{2} / 2 \text { if } d_{i} \leq\left(w_{i}-c_{i}\right) / v_{i}, \\
T_{i}\left(\left(w_{i}-c_{i}\right) / v_{i}\right)+c_{i}\left(d_{i}-\left(w_{i}-c_{i}\right) / v_{i}\right) \\
\text { otherwise, }
\end{array}\right.
$$

where $w_{i}$ and $v_{i}$ are parameters, and $v_{i} \in[0, \bar{v})$ and $\bar{v}=2 \beta_{i}-\left(\gamma_{i}+\gamma_{j}\right)$. Note that wholesale-price contracts are a subset of these quantity discounts-a wholesale-price contract can be obtained by setting $v_{i}=0$. Although we only consider a subset of possible quantity discounts, this is not overly restrictive. Our quantity discounts are continuous, differentiable, concave, and the manufacturer does not sell even the marginal unit for less than its production cost (which is the reason for the breakpoint at $\left.\left(w_{i}-c_{i}\right) / v_{i}\right)$. The upper bound on $v_{i}$ implies that the quantity discount is not too "aggressive" in the sense that the marginal price paid does not fall too rapidly as the purchase volume increases, i.e., $T_{i}^{\prime \prime}\left(d_{i}\right) \geq-v_{i}$. In fact, it can be shown that our quantity discounts are optimal for the manufacturer (holding the other manufacturer's contract offer fixed) among all concave and increasing payment functions given the $T_{i}^{\prime \prime}\left(d_{i}\right) \geq-v_{i}$ constraint (see Proposition 2 in the appendix). Furthermore, $T_{i}^{\prime \prime}\left(d_{i}\right) \geq-v_{i}$ ensures that the retailer's profit function excluding the operational costs is strictly concave in $\left(d_{1}, d_{2}\right)$. This naturally raises the question of whether the manufacturer could do better by offering an even more aggressive quantity discount. In a single-product environment, the answer is "no": as $v_{i}$ approaches $\bar{v}$, the supply chain's profit is maximized and the manufacturer earns all of that profit. In a twoproduct environment, the answer is not clear because retail profits are no longer strictly concave with $v_{i} \geq \bar{v}$. However, the next contract we describe can be interpreted as the most aggressive quantity discount, and we do have results for those contracts. 
Our third contract type is the two-part tariff, which is characterized by a fixed fee $F_{i}$ and a marginal cost $w_{i}$ :

$$
T_{i}\left(d_{i}\right)=F_{i} 1_{\left\{d_{i}>0\right\}}+w_{i} d_{i},
$$

where indicator function $1_{\left\{d_{i}>0\right\}}=\left\{1\right.$ if $d_{i}>0$, 0 otherwise $\}$. The two-part tariff is an aggressive quantity-discount contract because the marginal cost of the first unit is $F_{i}$, whereas the marginal cost of all subsequent units is only $w_{i}$ (which is generally much smaller than $F_{i}$ ).

In a symmetric game across manufacturers, the data for the two products are identical, i.e., $c_{i}, \theta_{i}, \beta_{i}, \gamma_{i}, K_{i}$, and $v_{i}$ are the same for any $i$. The subscript $i$ will be dropped in those cases. In a symmetric solution, the decisions $\left(d_{i}\right.$ at the retail level, $w_{i}$ or $T_{i}$ at the manufacturer level) are identical across products.

In the following sections, we solve the problem using backward induction. We analyze the retailer's decision first and then the game between the manufacturers.

\section{The Retailer's Decision}

This section studies the retailer's quantity decisions given the two contract offers from the manufacturers. We present the analysis assuming the manufacturers offer the retailer quantity discounts, which is sufficient to understand the retailer's decision under any of the three contract forms we consider: wholesaleprice contracts are quantity discounts with $v_{i}=0$, and, from the perspective of choosing demand rates for the products, two-part tariffs are identical to wholesale-price contracts (because the fixed fees do not matter for the retailer's pricing decisions given an assortment).

Define

$$
\begin{gathered}
d_{i}\left(d_{j}\right)=\underset{d_{i}}{\arg \max }\left\{\pi_{i}\left(d_{i}, d_{j}\right)\right\}, \\
\left(\tilde{d}_{i}, \tilde{d}_{j}\right)=\underset{d_{i}, d_{j}}{\arg \max }\left\{\pi\left(d_{i}, d_{j}\right): d_{i} d_{j}>0\right\}, \\
\tilde{\pi}=\pi\left(\tilde{d}_{i}, \tilde{d}_{j}\right),
\end{gathered}
$$

where $d_{i}\left(d_{j}\right)$ is the retailers optimal demand for product $i$ given a demand choice for product $j,\left(\tilde{d}_{i}, \tilde{d}_{j}\right)$ is the pair of optimal demands conditional that each product is included in the assortment (with some positive sales), and $\tilde{\pi}$ is the retailer's resulting profit.

The retailer's optimization problem can now be written as

$$
\max \left\{\tilde{\pi}, \pi_{1}\left(d_{1}(0), 0\right), \pi_{2}\left(0, d_{2}(0)\right)\right\} .
$$

Hence, the optimal solution to the retailer's problem is

$$
\left(d_{1}^{*}, d_{2}^{*}\right) \in\left\{\left(\tilde{d}_{1}, \tilde{d}_{2}\right),\left(d_{1}(0), 0\right),\left(0, d_{2}(0)\right)\right\} .
$$

For expositional simplicity, we assume that the retailer breaks ties in favor of carrying a full product line over a single product.

Consider the problem of maximizing the system's profit (i.e., the total profit across the three firms). It is equivalent to the retailer's problem if the manufacturers charge only their production cost, $T_{i}\left(d_{i}\right)=c_{i} d_{i}$ for $i=1,2$. Define $\widehat{\pi}_{1}=\pi_{1}\left(d_{1}(0), 0\right), \widehat{\pi}_{2}=\pi_{2}\left(0, d_{2}(0)\right)$, and $\widehat{\pi}_{12}=\pi\left(\tilde{d}_{1}, \tilde{d}_{2}\right)$ under those contracts. These profit levels are, respectively, the maximum profit the system would earn if it were to carry only product 1 , only product 2, and both products. We assume

$$
\widehat{\pi}_{12}>\widehat{\pi}_{i}>0 \text { for } i=1,2,
$$

which implies that it is always optimal for the system to carry both products.

Holding manufacturer 2's contract offer fixed, the retailer's reservation profit for accepting manufacturer 1 's offer is $\pi_{2}\left(0, d_{2}(0)\right)$, i.e., the retailer accepts manufacturer 1's offer only if adding product 1 to the assortment increases her profit over what she could earn without it in the assortment. To evaluate manufacturer 1's incremental profit, assume manufacturer 1 charges only his production costs, $T_{1}\left(d_{1}\right)=c_{1} d_{1}$, while holding manufacturer 2 's offer fixed. In that case, manufacturer 1's incremental profit is

$$
\max \left\{\tilde{\pi}, \pi_{1}\left(d_{1}(0), 0\right)\right\}-\pi_{2}\left(0, d_{2}(0)\right),
$$

where the first term is the most the product 1 supply chain can earn (conditional on product 2's contract), and the second term is the retailer's reservation profit.

Now let us consider the retailer's demand decision with independent manufacturers. Let $H_{i}$ denote the first derivative of $\pi$ with respect to $d_{i}$ :

$$
\begin{array}{r}
H_{i}=\partial \pi / \partial d_{i}=\theta_{i}-2 \beta_{i} d_{i}-\left(\gamma_{i}+\gamma_{j}\right) d_{j}-G_{i}^{\prime}\left(d_{i}\right)-T_{i}^{\prime}\left(d_{i}\right), \\
j \neq i . \quad(9)
\end{array}
$$

Consider the case with no economies of scale (i.e., $K_{1}=K_{2}=0$ ). The retailer's profit function $\pi$ is jointly concave in $\left(d_{1}, d_{2}\right)$, so the unique solution to $\left\{H_{i}=0\right.$, $i=1,2\}$ is the unique optimal solution. If an interior solution does not exist, then the optimal solution is either $\left(d_{1}(0), 0\right)$ or $\left(0, d_{2}(0)\right)$, where $d_{i}(0)$ is the unique solution to $H_{i}=0$ with $d_{j}=0$. Because $\pi$ is well behaved, the optimal solution $\left(d_{1}^{*}, d_{2}^{*}\right)$ can be easily characterized, and it is a continuous, differentiable function of the problem inputs such as the parameters of the manufacturers' contracts.

The case with economies of scale, however, is rather complicated. Observe that $\partial^{2} \pi / \partial d_{i}^{2}=-2 \beta_{i}-G_{i}^{\prime \prime}\left(d_{i}\right)-$ $T_{i}^{\prime \prime}\left(d_{i}\right)$ is positive at $d_{i}=0$ and then decreasing in $d_{i}$. Thus, $\pi$ is convex-concave in $d_{i}$ for fixed $d_{j}$. There are up to two solutions to $H_{i}=0$ and the larger of the two solutions is a local maximum. The corner solution, 
$d_{i}(0)$, is either the larger solution or zero. Evidently, $\pi$ is not jointly concave in $\left(d_{i}, d_{i}\right)$. As a result, there may be multiple solutions to $\left\{H_{i}=0, i=1,2\right\}$, and we do not know which one could be the interior optimal solution. Furthermore, the global optimal solution may be at one of the boundaries $d_{i}=0$. A final technical note is that the profit function is not necessarily unimodal (in one or two dimensions).

The next theorem shows that there can be at most one interior local maximum and that the optimal solution is either that interior solution or at one of the boundary lines; that is, there are at most three candidate optimal solutions and each is characterized by a set of first-order conditions. Furthermore, in a symmetric problem, the unique interior maximum is a symmetric solution.

THEOREM 1. The retailer's optimal solution is $\left(d_{1}^{*}, d_{2}^{*}\right) \in$ $\left\{\left(\tilde{d}_{1}, \tilde{d}_{2}\right),\left(d_{1}(0), 0\right),\left(0, d_{2}(0)\right)\right\}$, where $\left(\tilde{d}_{1}, \tilde{d}_{2}\right)$ is the unique interior optimal solution to $\left\{H_{i}=0, i=1,2\right\}$, and $d_{i}(0)$ is given by the larger of the two solutions to $\left\{H_{i}=0\right.$, s.t. $\left.d_{j}=0\right\}$. In a symmetric problem, $\left(\tilde{d}_{1}, \tilde{d}_{2}\right)=(\tilde{d}, \tilde{d})$, where $\tilde{d}$ is the larger of the two solutions to

$$
\theta-2(\beta+\gamma) d-G^{\prime}(d)-T^{\prime}(d)=0 .
$$

In summary, there are at most three local maxima for a retailer's problem: one interior solution in which the retailer carries both products, and two boundary solutions in which the retailer carries only one product.

Although the retailer's profit function is generally complex in the presence of economies of scale, the following conditions ensure that it is jointly concave in $\left(d_{1}, d_{2}\right)$. We state and prove this result in Lemma 1 in the appendix.

$$
\begin{gathered}
\beta_{1}=\beta_{2}=\beta, \quad \gamma_{1}=\gamma_{2}=\gamma, \\
T_{i}^{\prime \prime}\left(d_{i}\right) \geq-v_{i}, \quad \text { where } 0 \leq v_{i}<\bar{v}=\beta-\gamma, \\
2 R_{i} / G_{i} \geq\left|\varepsilon_{i i}\right| \quad \text { for all } i, \\
\text { where } \varepsilon_{i i}=-\frac{\beta_{j}}{\beta_{i} \beta_{j}-\gamma_{i} \gamma_{j}} \frac{p_{i}}{d_{i}} .
\end{gathered}
$$

Condition (10) requires the own- and cross-price coefficients to be symmetric. This is not a very restrictive assumption, because we allow nonidentical $\theta_{i}$, which implies different demand rates and price elasticities for the products. Condition (11) is stricter than our earlier assumption: it requires the quantity discount to be less concave to guarantee the concavity of the retailer's profit function. Condition (12) stipulates that the own-price elasticity $\left(\varepsilon_{i i}\right)$ is less than two times the revenues-to-average inventory costs ratio of the product. (It is similar to the conditions Bernstein and Federgruen (2003) developed for decentralized retailers, and as they point out, the conditions hold for most retailers based on the industry data in Dun and Bradstreet (2006) and Tellis (1988).)

\section{Competition Between the Manufacturers}

In this section, we study the game between the manufacturers in contract offers. We begin with some observations that apply no matter what type of contract is offered. In §5.1, we characterize the game's equilibria when both manufacturers choose quantity-discount contracts, and $\$ 5.2$ provides the analogous analysis when the manufacturers choose two-part tariffs. Section 5.3 expands the manufacturers' strategy set to include all three contract types that we consider. Section 5.4 compares the equilibria under different contract types for the more analytically tractable case of symmetric products and no economies of scale in inventory costs.

In the game between the manufacturers, each one chooses his own best response $T_{i}\left(T_{j}\right)$ given the other manufacturer's contract offer $T_{j}$ :

$$
T_{i}\left(T_{j}\right)=\underset{T_{i}\left(d_{i}\right)}{\arg \max } \Pi_{i}\left(d^{*}\right) \text { for all } i,
$$

$$
\text { where } d^{*}=\arg \max \pi,
$$

and it is understood that $T_{i}\left(d_{i}\right)$ is chosen from a defined strategy space (e.g., quantity-discount contracts with a fixed $v$ ). An equilibrium of the game is a pair of contracts $\left(T_{i}^{*}, T_{j}^{*}\right)$ such that neither manufacturer has an incentive to offer a different contract.

The following remark demonstrates how the contracting problem with multiple manufacturers is different from that with a single manufacturer.

REMARK 1. For any fixed contract offered by manufacturer 2 such that $\pi_{2}\left(0, d_{2}(0)\right)>0$ :

1. Consider the set of contracts such that the retailer's payment to manufacturer 1 is a nondecreasing function of $d_{1}$. There does not exist a contract in this set such that the manufacturer can extract all of the profit from his product (i.e., it is not possible to have $\Pi_{1}>0$ and $\pi_{1}=0$ ).

2. The retailer accepts manufacturer 1 's contract offer and stocks both products only if

$$
\pi_{1}\left(\tilde{d}_{i}, \tilde{d}_{j}\right)+\pi_{2}\left(\tilde{d}_{i}, \tilde{d}_{j}\right) \geq \pi_{2}\left(0, d_{2}(0)\right) .
$$

Unlike in a supply chain with a single manufacturer, the first statement implies that a manufacturer must leave the retailer with some profit to induce the retailer to carry the manufacturer's product (see the appendix for a detailed proof). However, this does not mean that a single reservation profit exists. As described in $\S 1$, the right-hand side of (14) is the retailer's reservation profit with respect to manufacturer 1's contract offer, and it depends on the particular contract offered by manufacturer 2 . Hence, there does not exist a single reservation profit-the reservation profit is endogenously determined by the actions 
of the other manufacturer. Furthermore, it is not possible to replicate the dynamics of this model with a carefully designed serial supply chain and a fixed reservation profit. To explain, via a simple manipulation of (14), the retailer's reservation profit for product 1 alone is the right-hand side of

$$
\pi_{1}\left(\tilde{d}_{i}, \tilde{d}_{j}\right) \geq \pi_{2}\left(0, d_{2}(0)\right)-\pi_{2}\left(\tilde{d}_{i}, \tilde{d}_{j}\right),
$$

which depends on manufacturer 1 's contract offer (even if the other contract is held fixed), and therefore cannot be represented by a single value.

Before considering the equilibrium contract offers, we add an observation that rules out equilibria in which the retailer carries only one product in symmetric games.

REMARK 2. In a symmetric game between the manufacturers, there does not exist an equilibrium where $d_{i}=0$ for some $i$.

The result is due to (8), which guarantees that the inclusion of a manufacturer strictly increases system profit. Suppose there were an equilibrium in which manufacturer $i$ is excluded. Regardless of the fraction of $\widehat{\pi}_{i}$ the retailer earns, manufacturer $i$ can offer to sell to the retailer at $c_{i}+\varepsilon$ for an arbitrarily small $\varepsilon$, and then the retailer's profit increases if it carries product $i$. If $j$ is excluded as a result, it will react similarly and get its product included.

\subsection{Wholesale-Price and Quantity-Discount Contracts}

In this section, we consider the game between the manufacturers in which they make quantity-discount contract offers with a given $v_{i}=v_{j}$. Hence, the two manufacturers simultaneously announce their $w_{i}$ parameter to the retailer, then the retailer decides how much to sell of each product. Recall that wholesale-price contracts have $v_{1}=v_{2}=0$, and they are a special case of this analysis. In the presence of economies of scale (i.e., if $K_{i}>0$ for any $i)$, we assume that conditions (10) and (11) hold, and we restrict our attention to a region defined by (12). Define $w_{i}\left(w_{j}\right)=\max \left\{w_{i}: d_{j}^{*}\left(w_{i}, w_{j}\right)=0\right\}$, the maximum $w_{i}$ that makes the retailer exclude product $j$, and $\bar{w}_{i}\left(w_{j}\right)=\min \left\{w_{i}: d_{i}^{*}\left(w_{i}, w_{j}\right)=0\right\}$, the minimum wholesale price of $i$ that makes the retailer exclude product $i$. Note that $\underline{w}_{i}\left(w_{j}\right)$ may not exist for every $w_{j}$. In that case, set $\underline{w}_{i}\left(w_{j}\right)=c_{i}$. Define $w_{i}\left(w_{j}\right)$ as the best response of manufacturer $i$, which can be found via a line search between $\left[\underline{w}_{i}, \bar{w}_{i}\right]$.

The following theorem characterizes the unique symmetric equilibrium of the contract offer game.

Theorem 2. Consider a symmetric game in which the manufacturers offer quantity discounts. There exists a unique symmetric solution to

$$
d_{i}^{*}\left(w_{1}, w_{2}\right)+\left(w_{i}-v_{i}-c_{i}\right) \frac{\partial d_{i}^{*}}{\partial w_{i}}=0 \text { for all } i,
$$

denoted $\left(w_{1}^{*}, w_{2}^{*}\right)$, which is the unique candidate to be a symmetric equilibrium.

As can be seen in the proof Theorem 2, showing the unimodality of a manufacturer's profit in $w_{i}$ requires the use of the second-order properties of the retailer's optimal solution $\left(d_{1}^{*}, d_{2}^{*}\right)$. In the presence of economies of scale, we have shown that the retailer's decision problem is complex (e.g., not concave, not unimodal), and this creates significant challenges to the analysis of the game between the manufactures, which is "built on top" of the retailer's decision problem. These challenges are not present in other competition papers in the literature.

We cannot guarantee that the candidate point described in Theorem 2 is an equilibrium. We show that at $\left(w_{1}^{*}, w_{2}^{*}\right), w_{i}^{*}$ is a local optimum for manufacturer $i$, and $\Pi_{i}$ is concave for $w_{i}>w_{i}^{*}$. However, the optimal solution $w_{i}\left(w_{j}^{*}\right)$ may be different than $w_{i}^{*}$ in the range $\left[\underline{w}_{i}, w_{i}^{*}\right]$. If $w_{i}\left(w_{i}^{*}\right)=w_{i}^{*}$, then $\left(w_{1}^{*}, w_{2}^{*}\right)$ is indeed an equilibrium point. If not, then there exists no symmetric equilibrium.

Now consider the situation in which there are no economies of scale. This substantially simplifies the analysis of both the retailer's demand decisions and the manufacturers' contract offer problem. For any $\left(v_{1}, v_{2}\right)$ and asymmetric products, we can now guarantee joint concavity of the retailer's profit and the existence and the uniqueness of the equilibrium without the symmetry assumptions. The next theorem provides the closed form solutions for the demand rates and the contract parameters by solving the firstorder conditions given in Theorem 2 .

Theorem 3. With no economies of scale (i.e., $\left.K_{i}=0\right)$, there exists a unique equilibrium of the game in which the manufacturers offer quantity discounts. It is characterized by the following reaction functions and the optimal demand rates:

$$
\begin{gathered}
d_{i}^{*}=\frac{\left(2 \beta_{j}-v_{j}\right)\left(\theta_{i}-w_{i}\right)-\left(\gamma_{i}+\gamma_{j}\right)\left(\theta_{j}-w_{j}\right)}{\left(2 \beta_{i}-v_{i}\right)\left(2 \beta_{j}-v_{j}\right)-\left(\gamma_{i}+\gamma_{j}\right)^{2}}, \\
w_{i}^{*}\left(w_{j}\right)=\frac{\left[\eta_{j} \theta_{i}-\left(\gamma_{i}+\gamma_{j}\right)\left(\theta_{j}-w_{j}\right)\right]\left(\delta+v_{i} \eta_{j}\right)+c_{i} \eta_{j} \delta}{\eta_{j}\left(2 \delta+v_{i} \eta_{j}\right)},
\end{gathered}
$$

where $\eta_{j} \equiv 2 \beta_{j}-v_{j}$ and $\delta \equiv\left(2 \beta_{i}-v_{i}\right)\left(2 \beta_{j}-v_{j}\right)-\left(\gamma_{i}+\gamma_{j}\right)^{2}$.

\subsection{Two-Part Tariffs}

In this section, we consider the game between manufacturers who offer two-part tariff contracts.

THEOREM 4. The equilibrium of the two-part tariff game is $F_{i}^{*}=\widehat{\pi}_{12}-\widehat{\pi}_{j}$ and $w_{i}^{*}=c_{i}$ for $i=1,2, j=3-i$. Hence, $\Pi_{i}=\widehat{\pi}_{12}-\widehat{\pi}_{j}$ and $\pi=\widehat{\pi}_{1}+\widehat{\pi}_{2}-\widehat{\pi}_{12}$. 
In the two-part tariff equilibrium, each manufacturer charges $w_{i}=c_{i}$ so that the retailer maximizes their combined profits. The manufacturer then extracts his full incremental profit via its fixed fee, and the retailer earns her reservation profit on each product. However, this does not mean that the manufacturers earn a large profit or even more than the retailer. If the two products are close substitutes, then each manufacturer's incremental profit, $\widehat{\pi}_{12}-\widehat{\pi}_{j}$, can be quite small. To explain, imagine the products were perfect substitutes. In that case, the retailer can earn as much from selling just one as she can earn from selling both, i.e., $\widehat{\pi}_{12}=\widehat{\pi}_{1}=\widehat{\pi}_{2}$, and each manufacturer's incremental profit is then zero, leaving the manufacturers with zero profit and the retailer with $\widehat{\pi}_{1}>0$. This logic extends to the case of economies of scale. As economies of scale become stronger, $\widehat{\pi}_{12}$ decreases relative to $\widehat{\pi}_{1}$ or $\widehat{\pi}_{2}$ : selling both products is relatively less attractive than selling just one product when economies of scale increase because it becomes costly to fragment demand across multiple products. Hence, an increase in economies of scale should decrease each manufacturer's incremental profit, thereby resulting in lower profits for them and higher profits (in a relative sense) for the retailer.

\subsection{Contract Choice}

In the previous sections, we assumed that the manufacturers offered contracts from a limited set: wholesale-price contracts, quantity discounts with a fixed $v$ parameter, or two-part tariffs. This section considers the manufacturers equilibrium contract choice when the set of contracts available to them is expanded.

Suppose the manufacturers could choose any contract type to offer the retailer, i.e., the unrestricted contract offer game. According to the next corollary (whose proof is actually part of the proof of Theorem 4), restricting the firms to the set of two-part tariffs does not actually change the outcome of the game.

Corollary 1. Consider the contract choice game in which the manufacturers are free to choose any contract type and parameters. It is optimal for each firm to offer a two-part tariff with $w_{i}=c_{i}$, no matter what contract offer the other firm makes. Furthermore, the equilibrium of the two-part tariff game described in Theorem 4 is also an equilibrium of the unrestricted contract choice game.

Now suppose that two-part tariffs are not in the contract space and the manufacturers simultaneously offer a quantity discount $\left(w_{i}, v_{i}\right)$ where they are free to choose any $v_{i} \in[0, \hat{v}]$ for some $\hat{v}<\bar{v}$. In other words, they can choose to offer a wholesale-price contract $\left(v_{i}=0\right)$ or a quantity discount $\left(v_{i}>0\right)$. The next proposition indicates, as in supply chains with a single manufacturer, that a manufacturer prefers to offer a quantity-discount contract and, in particular, prefers more aggressive quantity discounts. Quantity discounts allow the manufacturer to improve supply chain coordination (i.e., reduce double marginalization) and to extract rents, so they are the preferred contract when the other manufacturer's contract is held fixed even when the retailer can adjust her demand allocations between the two products in response.

Proposition 1. In the quantity-discount game where the manufacturers can choose from among the set of quantity discounts, manufacturer i's profit strictly increases with $v_{i}$ at the optimal wholesale price $w_{i}^{*}$; that is, if a manufacturer is given the option to choose between three contractual forms with $v_{i} \in\{0, a, b\}$ such that $0<a<b$, then $\Pi_{i}\left(w_{i}^{*} \mid v_{i}=0\right)<\Pi_{i}\left(w_{i}^{*} \mid v_{i}=a\right)<\Pi_{i}\left(w_{i}^{*} \mid v_{i}=b\right)$.

The immediate implication of this proposition is that if the manufacturers are able to choose the quadratic parameter of their quantity discount as well as the starting wholesale price, each manufacturer's best response is to choose the most aggressive contract in our consideration set. The next corollary states that any equilibrium of this game would then have the most aggressive contracts by both manufacturers.

COROLlary 2. In the contract choice game in which the manufacturers simultaneously offer $\left(w_{i}, v_{i}\right)$ and they are free to choose any $v_{i} \in[0, \hat{v}]$ for some $\hat{v}<\bar{v}$, the equilibrium contracts are such that $v_{i}=\hat{v}$ for both manufacturers.

To summarize, in equilibrium, the manufacturers choose the most aggressive contract in their strategy set, be it a two-part tariff or a quantity discount.

\subsection{Comparison of Equilibria}

The previous section established that if the manufacturers are free to choose any contract they want to offer the retailer, in equilibrium they choose to offer two-part tariffs. We also characterized the equilibrium contract offers when the manufacturers' strategy set is restricted to only wholesale-price contracts or only quantity-discount contracts. In this section, we compare these various outcomes. To provide analytical tractability, we consider a system with symmetric products (i.e., identical $\theta_{i}, \beta_{i}, \gamma_{i}, c_{i}$, and $v_{i}$ ) and no economies of scale at the retailer (i.e., $K_{i}=0$ ). Furthermore, among the set of quantity discounts, we provide results in the limit as $v$ goes to $2(\beta-\gamma)$, the upper bound. (Recall that Corollary 2 indicates that the manufacturers would choose those quantity discounts if they are allowed to do so.)

Table 1 presents the equilibrium profit terms under the three contract types. The derivation of the profit expressions are presented under Theorem 7 in the appendix.

As indicated earlier, two-part tariffs maximize the system's combined profits, and Table 1 reveals that 
Table 1 Equilibrium Profits Under Wholesale-Price, Quantity-Discount, and Two-Part Tariff Contracts in the Case with Symmetric Products and No Economies of Scale

\begin{tabular}{lccc}
\hline Contract & $\begin{array}{c}\text { Manufacturer } \\
\left(\Pi_{i}\right)\end{array}$ & $\begin{array}{c}\text { Retailer } \\
(\pi)\end{array}$ & $\begin{array}{c}\text { Supply chain } \\
\left(\pi+\Pi_{1}+\Pi_{2}\right)\end{array}$ \\
\hline Wholesale price & $\frac{(\theta-c)^{2}(\beta)(\beta-\gamma)}{2(\beta+\gamma)(2 \beta-\gamma)^{2}}$ & $\frac{(\theta-c)^{2} \beta^{2}}{2(\beta+\gamma)(2 \beta-\gamma)^{2}}$ & $\frac{(\theta-c)^{2} \beta(3 \beta-2 \gamma)}{2(\beta+\gamma)(2 \beta-\gamma)^{2}}$ \\
$\begin{array}{c}\text { Quantity discount } \\
\text { as } v \rightarrow 2(\beta-\gamma)\end{array}$ & $\frac{(\theta-c)^{2}(\beta-\gamma)}{4(\beta+\gamma)^{2}}$ & $\frac{(\theta-c)^{2} \gamma}{(\beta+\gamma)^{2}}$ & $\frac{(\theta-c)^{2}}{2(\beta+\gamma)}$ \\
Two-part tariff & $\frac{(\theta-c)^{2}(\beta-\gamma)}{4 \beta(\beta+\gamma)}$ & $\frac{(\theta-c)^{2} \gamma}{2 \beta(\beta+\gamma)}$ & $\frac{(\theta-c)^{2}}{2(\beta+\gamma)}$ \\
\hline
\end{tabular}

our chosen quantity discounts do as well (this result does not generalize to other quantity-discount contracts). Nevertheless, the manufacturers are not able to extract their full incremental profit with quantity discounts (they earn less with those contracts than the two-part tariff), which implies the retailers is better off with quantity discounts than with two-part tariffs. Furthermore, it is straightforward to show that the wholesale-price contract fails to maximize the system's combined profits.

Suppose the products are perfect substitutes, i.e., $\gamma=\beta$. In this case, the incremental profit of each manufacturer is zero under all contract types. Therefore, at equilibrium, the manufacturers offer marginal cost pricing, resulting in system optimal profits, and the retailer captures all the profits; that is, all contracts are equivalent for all players.

When products are independent, i.e., $\gamma=0$, the system is equivalent to two independent supply chains, and each manufacturer is able to achieve supply chain optimal profit and extract all of it either with quantity discounts or two-part tariffs, but not with wholesale-price contracts. This case replicates the common assumption in the supply chain contracting literature with a monopolist manufacturer. If $\gamma$ is reduced further, $\gamma<0$, then the products are complements. Now, $\widehat{\pi}_{1}+\widehat{\pi}_{2}<\widehat{\pi}_{12}$ (i.e., selling both products together earns more than the sum of selling them individually). It follows that the retailer has no leverage over the manufacturers, and she earns zero profit, just as in the $\gamma=0$ case. Theorem 9 in the appendix provides further details for the equilibrium with complementary products.

Now we turn attention to the interesting situation with imperfect substitutes, $\gamma \in(0, \beta)$. The next theorem compares the manufacturers' profits with wholesale-price contracts to the other two types.

Theorem 5 (Manufacturers' Perspective). (i) The manufacturers' profits are higher under quantity discounts than wholesale-price contracts if and only if $\gamma<(3-\sqrt{7})$ $\beta \approx(0.354) \beta$. (ii) The manufacturers' profits are higher under twopart tariffs than wholesale-price contracts if and only if $\gamma<(2-\sqrt{2}) \beta \approx(0.586) \beta$.

Theorem 5 indicates that the manufacturers are better off with the sophisticated contracts only if the products are not close substitutes, and this effect is stronger for the quantity discounts (in the sense that quantity discounts are preferred over a narrower parameter range). Note, holding the other manufacturer's contract offer fixed, a manufacturer always prefers a quantity-discount contract over the wholesale-price contract and a two-part tariff over the quantity discount. Hence, although they would choose two-part tariffs if they are not restricted in their contract choice, they would be better off had they been restricted to offer only wholesale-price contracts. In effect, the contract choice game is like the classic prisoner's dilemma.

The manufacturers may be worse off in equilibrium with the sophisticated contracts because the degree of product substitutability, $\gamma$, influences both a contract's incremental profit as well as the share of that profit that the manufacturer can extract from the retailer. To illustrate this explicitly, the following are the incremental profit of a manufacturer under the three contract types given the equilibrium contract offer from the competitor (derivations are presented in Theorem 8 in the appendix):

$$
\begin{gathered}
I P^{W}(\gamma)=\frac{(\theta-c)^{2}(2 \beta)(\beta-\gamma)}{2(\beta+\gamma)(2 \beta-\gamma)^{2}}, \\
I P^{Q}(\gamma)=I P^{T}(\gamma)=\frac{(\theta-c)^{2}(\beta-\gamma)}{4 \beta(\beta+\gamma)},
\end{gathered}
$$

where the superscripts $W, Q$, and $T$ denote the wholesale-price, quantity-discount, and two-part tariff contracts, respectively. It is straightforward to show that the wholesale-price contract has the highest incremental profit: $I P^{W}(\gamma)>I P^{Q}(\gamma)$ for all $\gamma \in(0, \beta)$. This holds because adding product $A$ to the retailer's assortment increases the retailer's profit more when manufacturer B offers a contract that does not maximize the total profit from product B (a wholesaleprice contract) relative to when manufacturer $B$ offers a contract that does maximize product B's profit (the two sophisticated contracts). It is also worth noting that the wholesale-price contract's relative advantage in incremental profit increases as the products become more substitutable ( $\gamma$ increases):

$$
\frac{I P^{W}(\gamma)}{I P^{Q}(\gamma)}=\frac{4 \beta^{2}}{(2 \beta-\gamma)^{2}}>1
$$

The drawback of the wholesale-price contract is that it captures only a fraction of its incremental profit, one-half of it to be precise, for all $\gamma$. Even the 
quantity-discount contract extracts only a fraction of its incremental profit, $\beta /(\beta+\gamma)$, but it is greater than one-half in the range of interest (though, it is also decreasing in $\gamma$ ). Putting these results together, if products are close substitutes, half of a large incremental profit (under wholesale-price contracts) may be larger than a larger share of a smaller incremental profit (under sophisticated contracts).

Now, let us consider the problem from the retailer's perspective. The next theorem compares the retailer's equilibrium profits under the three contract types.

Theorem 6 (Retailer's Perspective). (i) The retailer's profit is higher under quantity discounts than wholesale-price contracts if and only if $\gamma>\frac{1}{2}(3-\sqrt{7}) \beta \approx$ (0.177) $\beta$.

(ii) The retailer's profit is higher under two-part tariffs than wholesale-price contracts if and only if $\gamma>\frac{1}{2}(3-\sqrt{5}) \beta \approx(0.382) \beta$.

With a single manufacturer, the retailer is worse off with quantity discounts and two-part tariffs because they enable the manufacturer to extract rents from the retailer, leaving her with her reservation profit (possibly zero). However, when the manufacturers compete, the outcome is quite different. Now the retailer is better off with the more sophisticated contracts whenever the products are sufficiently close substitutes. These more sophisticated contracts increase the system's total profit and as long as the products are close substitutes; the lion's share of that profit goes to the retailer (because the manufacturers' incremental profits are small).

Figure 2 illustrates under which contract equilibrium the manufacturers' and the retailer are better off for different levels of substitutability. As already discussed, for high values of $\gamma$, the retailer prefers the sophisticated contracts because they lead to low incremental profits for the manufacturers, and the manufacturers have the opposite preference-although total rents in the system are lower with wholesaleprice contracts and those contracts cannot extract rents as efficiently (they earn only a fraction of their incremental profit), when $\gamma$ is high they prefer the wholesale-price contract. When $\gamma$ is low, the manufacturers prefer the rent extracting ability of the sophisticated contracts because their incremental profits remain reasonably high. The retailer is worse off with the sophisticated contracts because the manufacturer's extract a large chunk of the system's profit. Hence, for low and high levels of product substitutability, the manufacturers' preference is the opposite of the retailer's preference. However, for intermediate values of $\gamma$, they both prefer the sophisticated contracts. As with all $\gamma$, the sophisticated contracts increase the system's total profit (i.e., coordinates the system), but now both the manufacturers and the retailer are better off because the manufacturers' incremental profits are neither too high (as with a low $\gamma$ ) nor too low (as with a high $\gamma$ ).

As mentioned, the manufacturers face the classic prisoner's dilemma when the products are close substitutes. In a single-period game context, they always offer the more sophisticated contracts at equilibrium, but they prefer the system in which they both offer wholesale-price contracts. In a repeated game setting, the Folk Theorem suggests that they could theoretically coordinate (on offering wholesale-price contracts) using trigger-type punishment strategies. (This requires the ability to observe the competitor's contract type, which may be theoretically inferred from the retail prices.) In this case, the retailer may offer side payments to bring the manufacturers to the system-efficient outcome (sophisticated contracts). When products are not so close substitutes, the equilibrium under sophisticated contracts is preferred by the manufacturers, but not by the retailer. In practice, the bargaining powers of the firms in the negotiation

Figure 2 Equilibrium Preferences of the Firms for Different Levels of Substitutability

Wholesale-price vs. quantity-discount contracts

\begin{tabular}{|c|c|c|}
\hline \multirow[b]{2}{*}{ Manufacturers } & $\gamma<(0.354) \beta$ & $\gamma>(0.354) \beta$ \\
\hline & Quantity discount & Wholesale price \\
\hline \multirow[t]{2}{*}{ Retailer } & $\begin{array}{c}\text { Wholesale } \\
\text { price }\end{array}$ & Quantity discount \\
\hline & $\gamma<(0.177)$ & $\gamma>(0.177) \beta$ \\
\hline
\end{tabular}

Wholesale-price contracts vs. two-part tariffs

$\gamma<(0.586) \beta$

$\gamma>(0.586) \beta$

\begin{tabular}{|c|c|c|}
\hline Manufacturers & Two-p & Wholesale price \\
\hline \multirow[t]{2}{*}{ Retailer } & Wholesale price & Two-part tariff \\
\hline & $\gamma<(0.382) \beta$ & $\gamma>(0.382) \beta$ \\
\hline
\end{tabular}


process determine which of these outcomes will be observed.

Although our findings bear a resemblance to those in McGuire and Staelin (1983), there are some important distinctions. In McGuire and Staelin (1983), two manufacturers sell through dedicated retailers (i.e., the retailers only carry one of the manufacturers' products). As in our model, the manufacturers may prefer the equilibrium with wholesale-price contracts relative to the equilibrium under vertical integration, which can be achieved with two-part tariffs or quantity discounts. But the mechanism for this result is different-in their model, wholesale-price contracts dampen competition between the retailers, which indirectly dampens competition between the manufacturers, whereas in our model wholesale-price contracts directly influence the competition between the manufacturers while leaving constant the indirect competition they face with consumers. In addition, in their model, the retailers always prefer the wholesale-price equilibrium because two-part tariffs always leave them with no profit, whereas in our model the retailer may prefer the two-part tariff equilibrium.

\section{Numerical Study}

This section presents a numerical study that compares the equilibrium solutions when the manufacturers offer wholesale-price, quantity-discount, and two-part tariff contracts. Our primary goals are to study scenarios with economies of scale $(K>0)$ and to measure the magnitude of the effects discussed earlier.
There are 108 scenarios formed by all combinations of the following parameters: $\theta=\{20,40\}, \beta=\{1,2,4\}$, $\gamma=\{0.25,0.5,0.75\} \times \beta, c=\{1,3\}, K=\{0,1,3\}$, and $\lambda=0.5$. With each scenario, we searched for an equilibrium under wholesale-price, quantity-discount, and two-part tariff contracts. With the $K=0$ scenarios, we included $v=\{0,0.5,0.95,1.8\} \times(\beta-\gamma)$, and with the $K>0$ scenarios, we included $v=\{0,0.5,0.95\} \times$ $(\beta-\gamma)$. In total there are 360 scenario/contract combinations. In 8 of the 108 scenarios, we were unable to find an equilibrium for at least one of the contracts (including five scenarios with wholesale-price contracts). The best response functions in those scenarios reveal that the effect of economies of scale is very strong at the retailer, and the manufacturers cycle between undercutting prices to get the retailer to exclude the other manufacturer and being undercut. In those scenarios, there also does not exist an asymmetric equilibrium. We report results for the remaining 100 scenarios. As a validity check, we compared the average cost per unit that the retailer pays to the manufacturers, $T^{*}(d) / d$, with wholesale-price and quantity-discount contracts: the average cost is $5 \%$ lower in the quantity-discount equilibrium than the wholesale-price equilibrium when $v=0.5(\beta-\gamma)$, and $11 \%$ lower when $v=0.95(\beta-\gamma)$. These results indicate that in these scenarios the quantity discounts in equilibrium are modest.

Table 2 compares the firms' profits under wholesale-price contracts to the other contracts. The results in the table expand upon our intuition developed analytically in the previous section with $K=0$ and the most aggressive quantity discount $(v$ at its

Table 2 Average Percentage Change in the System, Retailer, and Manufacturer Profits in Equilibrium Under Quantity-Discount and Two-Part Tariff Contracts Relative to the Equilibrium Under Wholesale-Price Contracts

\begin{tabular}{|c|c|c|c|c|c|c|c|c|c|c|}
\hline \multirow[b]{3}{*}{ Change in profit } & \multicolumn{4}{|c|}{$K=0$} & \multicolumn{3}{|c|}{$K=1$} & \multicolumn{3}{|c|}{$K=3$} \\
\hline & \multicolumn{3}{|c|}{ Quantity discount (\%) } & \multirow{2}{*}{$\begin{array}{l}\text { Two-part } \\
\text { tariff (\%) }\end{array}$} & \multicolumn{2}{|c|}{ Quantity discount (\%) } & \multirow{2}{*}{$\begin{array}{l}\text { Two-part } \\
\text { tariff }(\%)\end{array}$} & \multicolumn{2}{|c|}{ Quantity discount (\%) } & \multirow{2}{*}{$\begin{array}{l}\text { Two-part } \\
\text { tariff }(\%)\end{array}$} \\
\hline & $\nu=0.5(\beta-\gamma)$ & $\nu=0.95(\beta-\gamma)$ & $\nu=1.8(\beta-\gamma)$ & & $\nu=0.5(\beta-\gamma)$ & $\nu=0.95(\beta-\gamma)$ & & $\nu=0.5(\beta-\gamma)$ & $\nu=0.95(\beta-\gamma)$ & \\
\hline \multicolumn{11}{|l|}{$\gamma=0.25 \times \beta$} \\
\hline System & 5.7 & 11.2 & 21.3 & 22.5 & 5.8 & 11.3 & 22.6 & 6.0 & 11.8 & 22.9 \\
\hline Retailer & 3.3 & 6.0 & 14.7 & -23.4 & 3.2 & 5.9 & -20.1 & 3.3 & 6.1 & -11.2 \\
\hline Manufacturers & 7.3 & 14.6 & 25.8 & 53.1 & 7.5 & 14.8 & 50.2 & 7.7 & 15.2 & 43.6 \\
\hline $\begin{array}{l}\text { Scenarios } \\
\text { manu. lose (\%) }\end{array}$ & 0 & 0 & 0 & 0 & 0 & 0 & 0 & 0 & 0 & 0 \\
\hline \multicolumn{11}{|l|}{$\gamma=0.5 \times \beta$} \\
\hline System & 3.5 & 6.8 & 12.0 & 12.5 & 3.6 & 6.9 & 12.4 & 3.7 & 7.1 & 12.1 \\
\hline Retailer & 6.2 & 13.8 & 38.5 & 12.5 & 6.6 & 14.7 & 16.3 & 7.1 & 15.8 & 25.6 \\
\hline Manufacturers & 0.8 & -0.2 & -14.5 & 12.5 & 0.7 & -0.6 & 8.6 & 0.5 & -1.2 & -0.3 \\
\hline $\begin{array}{l}\text { Scenarios } \\
\text { manu. lose (\%) }\end{array}$ & 0 & 100 & 100 & 0 & 0 & 100 & 0 & 0 & 100 & 41.7 \\
\hline \multicolumn{11}{|l|}{$\gamma=0.75 \times \beta$} \\
\hline System & 1.4 & 2.6 & 4.1 & 4.2 & 1.4 & 2.6 & 3.9 & 1.4 & 2.6 & 3.4 \\
\hline Retailer & 5.9 & 12.4 & 28.1 & 17.3 & 6.1 & 12.9 & 19.5 & 6.3 & 13.1 & 23.0 \\
\hline Manufacturers & -7.5 & -16.9 & -44.2 & -21.9 & -8.2 & -18.6 & -27.9 & -8.6 & -19.3 & -39.8 \\
\hline $\begin{array}{l}\text { Scenarios } \\
\quad \text { manu. lose (\%) }\end{array}$ & 100.0 & 100.0 & 100.0 & 100.0 & 100.0 & 100.0 & 100.0 & 100.0 & 100.0 & 100.0 \\
\hline
\end{tabular}

Note. manu., Manufacturers. 
upper bound). For any quantity discount ( $v$ is fixed), the manufacturers are better off if product substitutability, $\gamma$, is low, otherwise they are worse off. On the other hand, the percentage increase in the retailer's profit is not monotonic in $\gamma$ : the retailer gains the most with an intermediate level of product substitutability. When $\gamma$ is too low, the retailer does not gain as much because the manufacturers are able to extract a large portion of the system's increase in profit. When $\gamma$ is too high, the retailer does not gain as much because there is less to gain for everyone (i.e., the system's profit does not increase by a substantial amount). Interestingly, even with a low $\gamma$, the retailers may earn a higher profit with quantity discounts than with wholesale-price contracts-because the system becomes much more efficient, there is more profit available to share even if they are unable to gain a large fraction of it. Furthermore, these patterns are accentuated as $v$ increases or as $K$ increases (the shifts in profits become more dramatic as the manufacturers use more aggressive quantity discounts or if economies of scale become more pronounced).

According to Table 2, as with the quantity discounts, with two-part tariffs the manufacturers' are significantly better off when product substitutability is low and substantially worse off when $\gamma$ is high. However, the retailer is generally better off as $\gamma$ increases ( $K=3$ is the only exception). In sharp contrast to the case with quantity discounts, when $\gamma$ is low, the retailers are worse off with two-part tariffsthe system's profit is increased substantially but the rent extraction capability of two-part tariffs leaves the retailer with even less than she had with the wholesale price contracts.

In summary, our results are consistent with our conjectures that more sophisticated contracts (i) increase the total profit of the system, thereby making it possible for all firms to gain, and (ii) lower the manufacturer's incremental profit, especially as the products become more substitutable ( $\gamma$ increases) or as economies of scale increase, or both, and (iii) that product substitutability and economies of scale influence the fraction of a manufacturer's incremental profit that he can extract from the retailer. These three factors combine to create complex dynamics. Nevertheless, we observe that the manufacturers are generally worse off when sophisticated contracts are used and product substitutability is high. The retailer has just cause to fear two-part tariffs when product substitutability is low and otherwise can gain substantially from them.

\section{Discussion}

This paper studies competing manufacturers who sell their products through a single retailer. In some ways this supply chain structure is similar to the commonly studied supply chain structure with a single manufacturer. For example, the manufacturer can use sophisticated contracts (quantity discount or two-part tariffs) to (i) increase the system's profits relative to wholesale-price contracts (i.e., supply chain coordination) and (ii) extract a large fraction of the manufacturer's incremental profit. Consequently, in equilibrium, the manufacturers choose the most aggressive contract available to them (aggressive in the sense that the retailer's marginal cost falls rapidly), just as a single manufacturer would. The key difference is that, unlike the exogenous incremental profit with a single manufacturer, their incremental profits are endogenous with competition. Furthermore, the manufacturers' incremental profits decrease as they use more sophisticated contracts, especially when the products are close substitutes or there are economies of scale in retailing. Hence, while quantity discounts and two-part tariffs can work to the advantage of a single manufacturer, they can work to the disadvantage of competing manufacturers.

Our results provide guidance to firms as they consider the contractual form they wish to negotiate. Unlike when dealing with only a single manufacturer, a retailer may wish to encourage competing manufacturers to offer sophisticated contracts. A manufacturer must be careful when choosing to offer a sophisticated contract. If the industry standard is currently wholesale-price contracts, then a manufacturer can gain from offering a sophisticated contract, but if a competing manufacturer responds, then the ensuing sequence of offers and counteroffers can lead them to an equilibrium in which they are worse off if products are close substitutes. In that case, the retailer may induce the manufacturers to offer the sophisticated contracts by using side payments. And conversely, the manufacturers may induce the retailer to accept sophisticated contracts when substitutability is low. Furthermore, our results reinforce the importance to manufacturers of investing to distinguish their products-manufacturers with strong brands (i.e., products that are not easily substitutable with a competitor's product) can benefit from the use of sophisticated contracts. Manufacturers also benefit when operational improvements are made in the supply chain to reduce the economies of scale associated with retailing.

We consider a diverse set of contracts, but other contracts have been observed in practiced and studied in the literature, such as buy backs, quantity flexibility, and revenue-sharing contracts. These contracts, like quantity discounts and two-part tariffs, are designed to improve supply chain coordination and extract rents. Consequently, we conjecture that even with those contracts, the concept of an incremental profit holds along with our qualitative results. 
Our findings also yield empirically testable hypotheses. For example, the prevalence of quantitydiscount contracts could be correlated with the substitutability of products within a product category and the power of retailers and manufacturers to dictate contractual forms. There is anecdotal evidence from our conversations with executives from grocery retail chains (H-E-B in Texas and Stop \& Shop in the northeastern United States) that, in most categories, most firms offer the same type of contracts and the retailers make most of their money from incentives in categories with low brand loyalty (i.e., high substitutability). Buzzell et al. (1990) suggest that as major retailers grow and increase their relative power, they use it to extract concessions from suppliers such as trade deals, merchandising support, and slotting allowances in the consumer packaged goods industry. These observations have the same tone with our main result that retailers stand to gain more from the use of more sophisticated contracts.

\section{Acknowledgments}

The authors thank Awi Federgruen, Leslie Marx, Richard Staelin, and the anonymous review team for their helpful comments.

\section{Appendix. Proofs}

Proof of Theorem 1. The proof holds for general quantity discount contracts that satisfy

$$
\begin{gathered}
T_{i}(0)=0, \quad T_{i}^{\prime}(d) \geq c_{i}, \quad-v_{i} \leq T_{i}^{\prime \prime}(d) \leq 0, \\
T^{\prime \prime \prime}(d) \geq 0, \quad T^{\prime \prime \prime \prime}(d) \leq 0 .
\end{gathered}
$$

The quantity-discount contract given by (2) satisfies these conditions. The proof consists of two steps. The first step proves that the retailer's problem would not admit more than one local maximum in $\left\{\left(d_{i}, d_{j}\right): d_{i}>0\right.$ for $i=1,2\}$. The second step characterizes each of the solutions $\left(\tilde{d}_{1}, \tilde{d}_{2}\right),\left(\tilde{d}_{1}(0), 0\right),\left(0, \tilde{d}_{2}(0)\right)$. The proof of the first step is by contradiction. Suppose that there are two interior local maxima: $\left(x^{\prime}, y^{\prime}\right)$ and $\left(x^{\prime \prime}, y^{\prime \prime}\right)$. The line that connects $\left(x^{\prime}, y^{\prime}\right)$ and $\left(x^{\prime \prime}, y^{\prime \prime}\right)$ can be characterized by $\left(x^{\prime}+\alpha t, y^{\prime}+\delta t\right)$, where $\alpha=x^{\prime \prime}-x^{\prime}, \delta=y^{\prime \prime}-y^{\prime}, \alpha, \delta \in \Re, t \in[0,1]$ represents the line segment between the two points, and $t \in \Re$ represents the whole line. Define $\Delta(t)$ as the value of $\pi$ on that line,

$$
\Delta(t)=\pi\left(x^{\prime}+\alpha t, y^{\prime}+\delta t\right)
$$

We have

$$
\Delta^{\prime}(t)=\frac{\partial \pi}{\partial d_{i}} \frac{\partial d_{i}}{\partial t}+\frac{\partial \pi}{\partial d_{j}} \frac{\partial d_{j}}{\partial t}=\alpha \frac{\partial \pi}{\partial d_{i}}+\delta \frac{\partial \pi}{\partial d_{j}} .
$$

Because $\Delta(t)$ achieves local maxima at the points $\left(x^{\prime}, y^{\prime}\right)$ and $\left(y^{\prime}, x^{\prime}\right)$, we have $\Delta^{\prime}(t)=0$ and $\Delta^{\prime \prime}(t)<0$ at these points. We now derive higher-order derivatives:

$$
\begin{aligned}
\Delta^{\prime \prime \prime}(t)= & -\alpha^{3} G_{i}^{\prime \prime \prime}\left(x^{\prime}+\alpha t\right)-\delta^{3} G_{j}^{\prime \prime \prime}\left(y^{\prime}+\delta t\right) \\
& -\alpha^{3} T_{i}^{\prime \prime \prime}\left(x^{\prime}+\alpha t\right)-\delta^{3} T_{j}^{\prime \prime \prime}\left(y^{\prime}+\delta t\right), \\
\Delta^{\prime \prime \prime \prime}(t)= & -\alpha^{4} G_{i}^{\prime \prime \prime \prime}\left(x^{\prime}+\alpha t\right)-\delta^{4} G_{j}^{\prime \prime \prime \prime}\left(y^{\prime}+\delta t\right) \\
& -\alpha^{4} T_{i}^{\prime \prime \prime \prime}\left(x^{\prime}+\alpha t\right)-\delta^{4} T_{j}^{\prime \prime \prime \prime}\left(y^{\prime}+\delta t\right) .
\end{aligned}
$$

It follows that $\Delta^{\prime \prime \prime \prime}(t)>0$ because $G_{i}^{\prime \prime \prime \prime}\left(d_{i}\right)=-\lambda(1-\lambda)$. $(2-\lambda)(3-\lambda) K_{i} d_{i}^{\lambda-3}<0$ and $T_{i}^{\prime \prime \prime \prime} \leq 0$ by Equation (2). Therefore, $\Delta^{\prime \prime \prime}(t)$ is increasing.

Recall that $\Delta^{\prime}(t)=0$ and $\Delta^{\prime \prime}(t)<0$ at $t \in\{0,1\}$. Given that $\Delta(t)$ is continuous in $t$, this can only occur if there is at least one segment in $t \in[0,1]$ such that $\Delta^{\prime}(t)$ is convex-concave, which requires that $\Delta^{\prime \prime \prime}(t)$ is decreasing along some segment. However, we have established that $\Delta^{\prime \prime \prime}(t)$ is increasing, hence, a contradiction.

For the second step, it suffices to say that the interior optimal solution $\left(\tilde{d}_{1}, \tilde{d}_{2}\right)$ satisfies the first-order conditions $\left\{H_{i}=0, i=1,2\right\}$. The solution on the boundary $\left(\tilde{d}_{1}(0), 0\right)$ satisfies the first-order condition $\left\{H_{1}=0\right.$, s.t. $\left.d_{2}=0\right\}$. The same holds for $\left(0, \tilde{d}_{2}(0)\right)$.

It is easy to see that the profit function is convex-concave along the $d_{i}=0$ lines.

$$
\begin{gathered}
\partial \pi\left(d_{i}, 0\right) / \partial d_{i}=\theta_{i}-2 \beta_{i} d_{i}-G_{i}^{\prime}\left(d_{i}\right)-T_{i}^{\prime}\left(d_{i}\right), \\
\partial^{2} \pi\left(d_{i}, 0\right) / \partial d_{i}^{2}=-2 \beta_{i}-G_{i}^{\prime \prime}\left(d_{i}\right)-T_{i}^{\prime \prime}\left(d_{i}\right) .
\end{gathered}
$$

The second derivative is (i) decreasing in $d_{i}$, (ii) positive at $d_{i}=0$ (because $G_{i}^{\prime \prime}\left(d_{i}\right)=-\lambda(1-\lambda) K_{i} d_{i}^{\lambda-2} \rightarrow-\infty$ as $d_{i} \rightarrow 0^{+}$), and (iii) negative for sufficiently large $d_{i}$. Thus, there can be at most one local maximum for each problem.

For a symmetric problem, it follows from the above argument that the unique interior optimal solution is on the $d_{i}=d_{j}$ line. (If $\left(d_{i}, d_{j}\right)$ with $d_{i} \neq d_{j}$ is an interior optimal solution, then there are at least two local maxima, because $\left(d_{j}, d_{i}\right)$ is also an optimal solution by the symmetry of the profit function. This contradicts with the result above.) Similar to the boundary lines, the profit function is convexconcave on the $d_{i}=d_{j}$ line, and the solution is characterized by the first-order condition

$$
\partial \pi(d, d) / \partial d=\theta-2(\beta+\gamma) d-G^{\prime}(d)-T^{\prime}(d)=0 .
$$

LEMMA 1. The retailer profit function $\pi\left(d_{1}, d_{2}\right)$ is jointly concave in the region where $\left(d_{1}, d_{2}\right)$ satisfies $(12)$ and $T_{i}\left(d_{i}\right)$ satisfies (11).

Proof. First consider the retailer's problem under wholesale-price contracts from both manufacturers. We show that the Hessian is a negative semidefinite matrix, which guarantees joint concavity of the profit function. Note that (12) implies that $2 R_{i} / G_{i}=2 p_{i} d_{i} / G_{i}>\left(\beta /\left(\beta^{2}-\gamma^{2}\right)\right)$. $\left(p_{i} / d_{i}\right)$. First,

$$
\partial^{2} \pi / \partial d_{i}^{2}=-2 \beta+\lambda(1-\lambda) G_{i} d_{i}^{-2} \leq 0
$$

if and only if $\left(1 / \beta_{i}\right) p_{i} / d_{i} \leq 2 \lambda^{-1}(1-\lambda)^{-1} p_{i} d_{i} / G_{i}$, which is implied by (12), $\beta /\left(\beta^{2}-\gamma^{2}\right)>(1 / \beta)$, and $\lambda^{-1}(1-\lambda)^{-1} \geq 4$. Second, we show that the Hessian is a diagonally dominant matrix.

$$
\left|\partial^{2} \pi / \partial d_{i}^{2}\right|=2 \beta-\lambda(1-\lambda) G_{i} d_{i}^{-2} \geq\left|\partial^{2} \pi / \partial d_{j} \partial d_{i}\right|=2 \gamma
$$

if and only if $p_{i} / d_{i} \leq 2(\beta-\gamma) \lambda^{-1}(1-\lambda)^{-1} p_{i} d_{i} / G_{i}$, which holds under (12) if $\beta /\left(\beta^{2}-\gamma^{2}\right)>1 /(2 \beta-2 \gamma)$, or equivalently, $2 \beta>\beta+\gamma$.

The proof of the case with quantity-discount contracts is similar. To show diagonal dominance, we split the righthand side of the second derivatives to show $(\beta-\gamma)>-G_{i}^{\prime \prime}$ 
and $(\beta-\gamma)>-T_{i}^{\prime \prime}$. The former inequality holds by condition (12) and the latter by (11).

Proof of Remark 1. Suppose manufacturer 1 offers $T_{1}\left(d_{1}\right)$ and there exists a demand pair $\left(d_{1}^{\prime}, d_{2}^{\prime}\right)$ such that $\pi_{1}=0$. By definition, $\pi_{2}\left(d_{1}^{\prime}, d_{2}^{\prime}\right)=R_{2}\left(d_{1}^{\prime}, d_{2}^{\prime}\right)-T_{2}\left(d_{2}^{\prime}\right)-G_{2}\left(d_{2}^{\prime}\right)$. We have $\pi_{2}\left(d_{1}^{\prime}, d_{2}^{\prime}\right)<\pi_{2}\left(0, d_{2}^{\prime}\right) \leq \pi_{2}\left(0, d_{2}(0)\right)$. The first inequality is due to $\partial R_{2}^{\prime}\left(d_{1}, d_{2}\right) / \partial d_{1}<0$ for all $d_{1}, d_{2}$, and $T_{1}\left(d_{1}\right)$ is nondecreasing: the retailer can always increase her revenue from product 2 by dropping product 1 , and her payment to manufacturer 1 cannot increase. The second inequality follows by optimality of $d_{2}(0)$. Therefore, $\pi\left(0, \tilde{d}_{2}(0)\right)>\pi\left(d_{1}^{\prime}, d_{2}^{\prime}\right)$.

Proof of Proposition 1. The proof follows from the proof of Proposition 2.

Proposition 2. Among all quantity discounts that satisfy $T_{i}^{\prime \prime}\left(d_{i}\right) \leq-v_{i}$, the dominant strategy for manufacturer $i$ has the following functional form.

$$
T_{i}\left(d_{i}, w_{i}, v_{i}\right)=\left\{\begin{array}{l}
w_{i} d-v_{i} d_{i}^{2} / 2, \\
\quad \text { if } d_{i} \leq\left(w_{i}-c_{i}\right) / v_{i}, \\
T_{i}\left(\left(w_{i}-c_{i}\right) / v_{i}\right)+c_{i}\left(d_{i}-\left(w_{i}-c_{i}\right) / v_{i}\right) \\
\text { otherwise. }
\end{array}\right.
$$

Thus, for given $T_{j}\left(d_{j}, w_{j}, v_{j}\right)$ and fixed $v_{i}$, the best response of manufacturer $i$ is given by $T_{i}\left(d_{i}, w_{i}^{*}, v_{i}\right)$ for some $w_{i}^{*} \geq$ $\left[c_{i}, \theta_{i}\left(v_{i} / \beta_{i}+1\right)\right]$.

Proof. Without loss of generality, let $j=2$ and $i=1$. Take any $T_{1}\left(d_{1}\right)$ and $T_{2}\left(d_{2}\right)$. Suppose that the retailer's optimal solution is an internal point $\tilde{d}=\left(\tilde{d}_{1}, \tilde{d}_{2}\right)$. (The proof is simpler if one of $\tilde{d}_{i}$ is zero.) At the optimal solution, the first-order conditions are satisfied: $\left\{H_{1}=0, H_{2}=0\right\}$. Define $\tau$ such that

$$
\tau=H_{1}(\tilde{d})+T_{1}^{\prime}\left(\tilde{d}_{1}\right)=\frac{\partial\left(R_{1}(\tilde{d})+R_{2}(\tilde{d})-G_{1}\left(\tilde{d}_{1}\right)\right)}{\partial d_{1}} .
$$

We have $T_{1}^{\prime}\left(\tilde{d}_{1}\right)=\tau$. The optimal discount scheme for manufacturer 1 among those that generate $\tilde{d}$ is the solution to

$$
\begin{aligned}
\max & T_{1}\left(\tilde{d}_{1}\right) \\
\text { subject to } & H_{i}(\tilde{d})=0 \quad \text { for } i=1,2 .
\end{aligned}
$$

The constraints guarantee that both first-order conditions are satisfied at $\left(\tilde{d}_{1}, \tilde{d}_{2}\right)$. The retailer function is jointly concave everywhere in the absence of economies of scale at the retailer as long as $T_{i}$ satisfies $T_{i}^{\prime \prime}\left(d_{i}\right) \leq-v_{i}$. Thus, $\left(\tilde{d}_{1}, \tilde{d}_{2}\right)$ remains the optimal solution (and the unique local maximum) for the retailer. In the presence of economies of scale, $\left(\tilde{d}_{1}, \tilde{d}_{2}\right)$ remains the unique interior optimal solution for the retailer by Theorem 1 as long as $T_{i}$ satisfies (11). Because, the retailer profit is jointly concave when (10)-(12) are satisfied, $\left(\tilde{d}_{1}, \tilde{d}_{2}\right)$ remains the optimal solution in the region defined by (12).

The manufacturer's problem can be written as $\left\{\max T_{1}\left(\tilde{d}_{1}\right): T_{1}^{\prime}\left(\tilde{d}_{1}\right)=\tau\right\}$ because the condition implies $H_{1}(\tilde{d})=0$, and we already have $H_{2}(\tilde{d})=0$. Therefore, the objective is to increase $T_{1}\left(\tilde{d}_{1}\right)$ while keeping the marginal cost at $\tilde{d}_{1}$ the same. This can be achieved by reducing $T_{1}^{\prime}\left(d_{1}\right)$ as little as possible for all $d_{1}<\tilde{d}_{1}$, which can be achieved by setting $T_{1}^{\prime \prime}\left(d_{1}\right)=v_{1}$. Together with $T_{1}^{\prime}\left(\tilde{d}_{1}\right)=\tau$, this implies that

$$
T_{1}^{\prime}\left(d_{1}\right)=-v_{1}\left(d_{1}-\tilde{d}_{1}\right)+\tau \text { for all } d_{1} \in\left[0, \tilde{d}_{1}\right] .
$$

That is, the marginal cost to the retailer is decreasing as slowly as possible and equals $\tau$ at $\tilde{d}$. We have $T_{1}^{\prime \prime}\left(\tilde{d}_{1}\right)=-v_{1}$. The derivative payment $T_{1}^{\prime}\left(d_{1}\right)$ can be specified in any way for $d_{1}>\tilde{d}_{1}$ as long as it satisfies (15). We use the same functional form to specify $T_{1}^{\prime}\left(d_{1}\right)$ (which implies that $T_{1}^{\prime \prime}\left(d_{1}\right)=$ $-v)$ for all $d_{1}>\tilde{d}_{1}$ to make sure that the argument applies to all $\tilde{d}_{1}$. Another condition in (15) requires $T_{1}^{\prime}\left(d_{1}\right) \geq c_{1}$. The derivative payment $T_{1}^{\prime}$ is decreasing linearly in $d_{1}$, and it will reach $c_{1}$ at some finite value. Rewriting $T_{1}^{\prime}$, we replace $v_{1} \tilde{d}_{1}+\tau$ with $w_{1}$ to obtain

$$
T_{1}^{\prime}\left(d_{1}\right)= \begin{cases}w_{1}-v_{1} d_{1} & \text { for } d_{1} \leq\left(w_{1}-c_{1}\right) / v_{1}, \\ c_{1} & \text { for } d_{1}>\left(w_{1}-c_{1}\right) / v_{1} .\end{cases}
$$

Integrating $T^{\prime}$ and recalling the boundary value $T(0)=0$ by (15), we obtain the quantity-discount schedule

$$
T_{1}\left(d_{1}\right)=\left\{\begin{array}{l}
w_{1} d_{1}-v_{1} d_{1}^{2} / 2 \text { if } d_{1} \leq\left(w_{1}-c_{1}\right) / v_{1}, \\
T_{1}\left(\left(w_{1}-c_{1}\right) / v_{1}\right)+c_{1}\left(d_{1}-\left(w_{1}-c_{1}\right) / v_{1}\right) \quad \text { otherwise. }
\end{array}\right.
$$

Note that this is not the optimal discount scheme over all possible discount schemes. It is the best scheme among the ones that produce $\tilde{d}$. In other words, the functional form dominates other functional forms of $T_{1}\left(d_{1}\right)$. Thus, the optimal quantity-discount scheme can be found by considering the functions of this type only. We will see in Theorem 2 that the constant part of $T_{1}^{\prime}\left(d_{1}\right)$ is not relevant. A technical note is needed here that (15) requires continuous and differentiable payment functions, but the suggested solution has a nondifferentiable point. This can be circumvented by replacing the two-piece marginal cost function with a differentiable convex decreasing function that approximates it very closely.

The manufacturer profit is zero if $w_{1} \leq c_{1}$. It is also zero if $w_{1} \geq \theta_{1}\left(v_{1} / \beta_{1}+1\right)$, because the marginal cost to the retailer $w_{1}-v_{1} d_{1}>w_{1}-v_{1} \theta_{1} / \beta_{1}>\theta_{1}\left(v_{1} / \beta_{1}+1\right)-v_{1} \theta_{1} / \beta_{1}=\theta_{1}$, which implies zero demand. The first inequality is due to $d_{1} \leq \theta_{1} / \beta_{1}$ to keep $p_{1}$ nonnegative. If the retailer charges $\theta_{1}$ for product 1 , the demand cannot be positive, which implies that $\Pi_{i}=0$.

Proof of Theorem 2. Recall that $v_{i}=0$ when the manufacturers employ wholesale-price contracts. Furthermore, while evaluating the equilibrium, we need to only consider the quadratic part of the payment functions. Suppose by contradiction that the retailer chose $d_{i}$ such that $d_{i}>\left(w_{i}-c_{i}\right) / v_{i}$. The manufacturer can increase $w_{i}$ such that $d_{i}=\left(w_{i}-c_{i}\right) / v_{i}$ and increase his profit without affecting the retailer's or the other manufacturer's decisions.

We show in the proof that $\Pi_{i}$ is concave in $w_{i}$ at the symmetric solution to the first-order condition stated in the theorem. Hence, the solution is (at least) a local maximum.

Using the quadratic part of $T_{i}$, we obtain the first-order condition for a manufacturer as follows:

$$
\frac{\partial \Pi_{i}}{\partial w_{i}} \quad \text { at } w_{i}^{*}=d_{i}^{*}+\left(w_{i}-c_{i}-v_{i} d_{i}^{*}\right) \frac{\partial d_{i}^{*}}{\partial w_{i}}=0 .
$$

Applying the implicit function theorem on the retailer's first-order conditions $\left\{H_{i}=0\right.$ for all $\left.i\right\}$, we can derive the 
impact of the wholesale prices on the optimal demand rates. Define $A_{i}=\left(2 \beta_{i}+G_{i}^{\prime \prime}+T_{i}^{\prime \prime}\right), A_{i}^{\prime}=\partial A_{i} / \partial d_{i}=G_{i}^{\prime \prime \prime}=\lambda(1-\lambda)$. $(2-\lambda) d_{i}^{\lambda-3}=-(2-\lambda) d_{i}^{-1} G_{i}^{\prime \prime}>0, B=\left(\gamma_{i}+\gamma_{j}\right)$, and $\Delta=A_{i} A_{j}-B^{2}$. Note that $\Delta>0$ because of the diagonal dominance of the Hessian as shown in Lemma 1.

$$
\left[\begin{array}{c}
\partial d_{i}^{*} / \partial w_{i} \\
\partial d_{j}^{*} / \partial w_{i}
\end{array}\right]=\frac{1}{A_{i} A_{j}-B^{2}}\left[\begin{array}{c}
-A_{j} \\
\left(\gamma_{i}+\gamma_{j}\right)
\end{array}\right] .
$$

As expected, $d_{i}$ decreases with $w_{i}$ and increases with $w_{j}$. The second derivative of $\Pi_{i}$ yields

$$
2 \frac{\partial d_{i}^{*}}{\partial w_{i}}-v\left(\frac{\partial d_{i}^{*}}{\partial w_{i}}\right)^{2}+\left(w_{i}-c_{i}-v_{i} d_{i}^{*}\right) \frac{\partial^{2} d_{i}^{*}}{\partial w_{i}^{2}},
$$

which is negative when $d_{1}^{*}=d_{2}^{*}$, because we have $A_{1}^{\prime}=A_{2}^{\prime}$ and

$$
\begin{aligned}
\frac{\partial^{2} d_{i}^{*}}{\partial w_{i}^{2}} & =\Delta^{-2}\left[-A_{j}^{\prime} B \Delta^{-1} \Delta+A_{j}\left(A_{i} A_{j}^{\prime} B \Delta^{-1}+A_{i}^{\prime} A_{j}\left(-A_{j}\right) \Delta^{-1}\right)\right] \\
& =\Delta^{-3}\left[-A_{j}^{\prime} B \Delta+\left(A_{i} A_{j} A_{j}^{\prime} B-A_{i}^{\prime} A_{j}^{3}\right)\right] \\
& =\Delta^{-3}\left[-A_{j}^{\prime} B A_{i} A_{j}+A_{j}^{\prime} B^{3}+\left(A_{i} A_{j} A_{j}^{\prime} B-A_{i}^{\prime} A_{j}^{3}\right)\right] \\
& =\Delta^{-3}\left[-A_{i}^{\prime} A_{j}^{3}+A_{j}^{\prime} B^{3}\right]<0 .
\end{aligned}
$$

Hence, the first-order condition above has a unique solution when $d_{1}^{*}=d_{2}^{*}$. The solution $\left(w_{1}^{*}, w_{2}^{*}\right)$ satisfies the first- and second-order conditions for both manufacturers; that is, $w_{i}^{*}$ is a local maximum of $\Pi_{i}$ for fixed $w_{j}$, and vice versa. If $w_{i}>w_{i}^{*}$, then $d_{1}^{*}$ decreases and $d_{2}^{*}$ increases, $A_{i}^{\prime}$ increases, $A_{j}$ increases, and $A_{j}^{\prime}$ decreases, implying that $\partial^{2} d_{i}^{*} / \partial w_{i}^{2}$ remains negative. Hence, $\Pi_{i}$ is concave in $w_{i}$ for $w_{i}>w_{i}^{*}$ for fixed $w_{j}^{*}$. Thus, there can be no other local maximum greater than $w_{i}^{*}$, but a linear search in $\left[\underline{w}_{i}, w_{i}^{*}\right]$ is necessary to find the optimal wholesale price.

Proof of Theorem 3. The optimal demand rates can be solved as the unique solution to first-order conditions $\left\{H_{i}=0, i=1,2\right\}$ for given $\left(w_{1}, w_{2}\right)$. We have $\alpha \equiv \partial d_{i} / \partial w_{i}=$ $-\left(2 \beta_{j}-v_{j}\right) / \delta, \partial^{2} d_{i} / \partial w_{i}^{2}=0$, and $\partial^{2} d_{i} / \partial w_{i} \partial w_{j}=0, \partial d_{i} / \partial w_{j}=$ $\left(\gamma_{i}+\gamma_{j}\right) / \delta$. Substituting these in the first-order conditions in Theorem 2, we verify that the profit function of manufacturer $i$ is concave in $w_{i}$. This guarantees the existence of equilibria in the quantity-discount game between the manufacturers. The best response $w_{i}\left(w_{j}\right)$ is the explicit solution to each first-order condition. Differentiating, we obtain

$$
\begin{aligned}
\frac{\partial w_{i}}{\partial w_{j}} & =\frac{\left(1-v_{i} \alpha\right)\left(\gamma_{i}+\gamma_{j}\right) / \delta}{-2 \alpha+v_{i} \alpha^{2}} \\
& =\frac{\left(1-v_{i} \alpha\right)\left(\gamma_{i}+\gamma_{j}\right)}{\left(2 \beta_{j}-v_{j}\right)(2-v \alpha)}>0 \text { and }<1 .
\end{aligned}
$$

The second inequality is due to $v_{i}<2 \beta_{i}-\left(\gamma_{i}+\gamma_{j}\right)$. Hence, we have increasing reaction functions with a slope less than 1 . This implies that there is a unique equilibrium of the game between the manufacturers.

Proof of Theorem 4. The first part of the proof shows that for any set of contracts by the manufacturers, manufacturer $i$ can do better by switching to a two-part tariff $\left(F_{i}, c_{i}\right)$. Suppose manufacturer 2 is offering some contract to the retailer (it can be any contract that depends only on $d_{2}$ ). We will show that manufacturer 1 can do no better than to offer a two-part tariff. The retailer will accept any contract from manufacturer 1 as long as her profit is at least $\pi_{2}\left(0, d_{2}(0)\right) \geq 0$. Suppose manufacturer 1 offers to sell his product at marginal cost and $F_{1}=0$, so $\Pi_{1}=0$. In that case, define $\hat{\pi}$ to be the retailer's maximum profit given the two contract offers:

$$
\begin{aligned}
\widehat{\pi} & =\Pi_{1}+\max \left\{\tilde{\pi}, \pi_{1}\left(d_{1}(0), 0\right), \pi_{2}\left(0, d_{2}(0)\right)\right\} \\
& =\max \left\{\tilde{\pi}, \pi_{1}\left(d_{1}(0), 0\right), \pi_{2}\left(0, d_{2}(0)\right)\right\} .
\end{aligned}
$$

Hence, the retailer maximizes the combined profits of the two firms. manufacturer 1 's incremental profit is $\widehat{\pi}-$ $\pi_{2}\left(0, d_{2}(0)\right)$. We now show, by contradiction, that manufacturer 1 cannot earn more than his incremental profit. Suppose manufacturer 1 offers a contract, $T_{1}$, such that he earns more than his incremental profit,

$$
\Pi_{1}>\widehat{\pi}-\pi_{2}\left(0, d_{2}(0)\right)
$$

and the retailer earns at least her reservation profit (so she is willing to accept manufacturer 1's contract offer),

$$
\pi \geq \pi_{2}\left(0, d_{2}(0)\right)
$$

Add the above two equations to get

$$
\Pi_{1}+\pi>\widehat{\pi}
$$

which contradicts the fact that $\hat{\pi}$ is the upper bound on the firm's combined profits. Hence, manufacturer 1 cannot earn more than his incremental value. However, he can earn precisely his incremental value by choosing $F_{1}=\widehat{\pi}-$ $\pi_{2}\left(0, d_{2}(0)\right)$ and $w_{1}=c_{1}$. Therefore, he can do no better with any other contract.

The second part characterizes the equilibrium fees $\left(F_{1}^{*}, F_{2}^{*}\right)$. For any $\left(F_{1}, c_{1}\right),\left(F_{2}, c_{2}\right)$, we have $\Pi_{i}=F_{i} 1_{\left\{d_{i}^{*}>0\right\}}$, and $\pi=\max \left\{\hat{\pi}_{1}-F_{1}, \hat{\pi}_{2}-F_{2}, \widehat{\pi}_{12}-F_{1}-F_{2}, 0\right\}$. Let us focus on manufacturer 1 . If $F_{2} \leq \widehat{\pi}_{12}-\widehat{\pi}_{1}$, then $\widehat{\pi}_{1}-F_{1} \leq \widehat{\pi}_{12}-$ $F_{1}-F_{2}$ and $\pi=\max \left\{\hat{\pi}_{2}-F_{2}, \widehat{\pi}_{12}-F_{1}-F_{2}\right\}$, and manufacturer 1 's best response to $F_{2}$ is to set $F_{1}$ as high as possible while ensuring that $\widehat{\pi}_{12}-F_{1}-F_{2} \geq \widehat{\pi}_{2}-F_{2}$; hence, $F_{1}^{*}\left(F_{2}\right)=\widehat{\pi}_{12}-\widehat{\pi}_{2}$. If $\widehat{\pi}_{2} \geq F_{2}>\widehat{\pi}_{12}-\widehat{\pi}_{1}$, then $\widehat{\pi}_{1}-F_{1}>$ $\widehat{\pi}_{12}-F_{1}-F_{2}$ and $\pi=\max \left\{\widehat{\pi}_{1}-F_{1}, \widehat{\pi}_{2}-F_{2}\right\}$, and manufacturer 1's best response to $F_{2}$ is to set $F_{1}$ as high as possible while ensuring that $\widehat{\pi}_{1}-F_{1} \geq \widehat{\pi}_{2}-F_{2}$. Hence, $F_{1}^{*}\left(F_{2}\right)=$ $\widehat{\pi}_{1}-\widehat{\pi}_{2}+F_{2}-\varepsilon$ for arbitrarily small $\varepsilon$. If $F_{2}>\widehat{\pi}_{2}$, then $\widehat{\pi}_{1}-F_{1}>\widehat{\pi}_{12}-F_{1}-F_{2}$ and $\pi=\max \left\{\widehat{\pi}_{1}-F_{1}, 0\right\}$, and manufacturer 1 's best response is to set $F_{1}=\widehat{\pi}_{1}$. The best response function of manufacturer 2 is similarly obtained: $F_{2}^{*}\left(F_{1}\right)=\left\{\widehat{\pi}_{12}-\widehat{\pi}_{1}\right.$ if $F_{1} \leq \widehat{\pi}_{12}-\widehat{\pi}_{2}, \widehat{\pi}_{2}-\widehat{\pi}_{1}+F_{1}-\varepsilon$ otherwise $\}$. The unique equilibrium point is $\left(F_{1}^{*}, F_{2}^{*}\right)=\left(\widehat{\pi}_{12}-\widehat{\pi}_{1}\right.$, $\left.\widehat{\pi}_{12}-\widehat{\pi}_{1}\right)$, which are precisely the incremental profits of the manufacturers. At equilibrium, the retailer's profit is $\pi=\widehat{\pi}_{12}-\left(\widehat{\pi}_{12}-\widehat{\pi}_{1}\right)-\left(\widehat{\pi}_{12}-\widehat{\pi}_{2}\right)=\widehat{\pi}_{1}+\widehat{\pi}_{2}-\widehat{\pi}_{12}$. The retailer's profit is nonnegative, because $\widehat{\pi}_{12} \leq \widehat{\pi}_{1}+\widehat{\pi}_{2}$ follows from the substitutability of the products.

Proof of ThEOREM 5. Comparing the manufacturers' profit expressions given in Table 1, we see that profits under quantity discounts are always lower than those under twopart tariffs because $\beta<(\beta+\gamma)$. Profit under wholesaleprice contracts is less than that under quantity discounts if and only if $2 \beta(\beta+\gamma)<(2 \beta-\gamma)^{2}$, which is equivalent to $0<2 \beta^{2}-6 \beta \gamma+\gamma^{2}$. The right-hand side is equal to $2 \beta^{2}$ at 
$\gamma=0$ and $-3 \beta^{2}$ at $\gamma=\beta$, and it is decreasing in between, crossing zero only once at $\beta(3-\sqrt{7})$. Similarly, profit under wholesale-price contracts is less than that under two-part tariffs if and only if $\left(2 \beta^{2}\right)<(2 \beta-\gamma)^{2}$, which is equivalent to $\gamma<\beta(2-\sqrt{2})$.

Proof of Theorem 6. Comparing the retailer's profit expressions given in Table 1, we see that profits under quantity discounts are always higher than those under two-part tariffs because $2 \beta>(\beta+\gamma)$. Profit under wholesale-price contracts is less than that under quantity discounts if and only if $\beta^{2}(\beta+\gamma)-2 \gamma(2 \beta-\gamma)^{2}<0$. The left-hand side is positive for all $\gamma \leq 0$, it is equal to 0 at $\gamma=\beta$, and it is convex in between, implying at most a single crossing point in $(0, \beta)$, which would be the smallest root of this third-degree polynomial, i.e., $\frac{1}{2} \beta(3-\sqrt{7})$. Profit under wholesale-price contracts is less than that under two-part tariffs if and only if $\beta^{3}-\gamma(2 \beta-\gamma)^{2}<0$. The left-hand side is positive for all $\gamma \leq 0$, is equal to 0 at $\gamma=\beta$, and it is convex in between, implying at most a single crossing point in $(0, \beta)$, which would be the smallest root, i.e., $\frac{1}{2} \beta(3-\sqrt{5})$.

THEOREM 7. Equilibrium profits of the firms under each contract type are given in Table 1.

Proof. Start with the centralized system. The optimal demand rates and the profit are as follows:

$$
\begin{gathered}
{\left[\begin{array}{c}
d_{i}^{*} \\
d_{j}^{*}
\end{array}\right]=\frac{1}{4\left(\beta^{2}-\gamma^{2}\right)}\left[\begin{array}{cc}
2 \beta & -2 \gamma \\
-2 \gamma & 2 \beta
\end{array}\right]\left[\begin{array}{c}
\theta_{i}+c_{i} \\
\theta_{j}+c_{j}
\end{array}\right],} \\
d_{i}^{*}=\frac{\beta\left(\theta_{i}-c_{i}\right)-\gamma\left(\theta_{j}-c_{j}\right)}{2\left(\beta^{2}-\gamma^{2}\right)}, \quad p_{i}^{*}-c_{i}=\frac{\theta_{i}-c_{i}}{2}, \\
\widehat{\pi}_{i j}=\frac{\beta\left(\theta_{i}-c_{i}\right)^{2}+\beta\left(\theta_{j}-c_{j}\right)^{2}-2 \gamma\left(\theta_{j}-c_{j}\right)\left(\theta_{i}-c_{i}\right)}{4\left(\beta^{2}-\gamma^{2}\right)}, \\
\text { if symmetric: } \quad \widehat{\pi}_{i j}=2 \frac{(\theta-c)^{2}}{4(\beta+\gamma)} .
\end{gathered}
$$

If only product $i$ were carried, then

$p_{i}^{*}-c_{i}=\left(\theta_{i}-c_{i}\right) / 2, \quad d_{i}^{*}=\frac{\left(\theta_{i}-c_{i}\right)}{2 \beta}, \quad$ and $\quad \widehat{\pi}_{i}=\frac{\left(\theta_{i}-c_{i}\right)^{2}}{4 \beta}$.

Now consider the equilibrium under two-part tariffs. By Theorem 4, manufacturer $i$ 's optimal strategy is of a $\left(F_{i}, c_{i}\right)$ type two-part tariff.

$$
\begin{aligned}
\Pi_{i}= & F_{i}^{*}=\widehat{\pi}_{i j}-\widehat{\pi}_{j} \\
= & \frac{\beta\left(\theta_{i}-c_{i}\right)^{2}+\beta\left(\theta_{j}-c_{j}\right)^{2}-2 \gamma\left(\theta_{j}-c_{j}\right)\left(\theta_{i}-c_{i}\right)}{4\left(\beta^{2}-\gamma^{2}\right)}-\frac{\left(\theta_{j}-c_{j}\right)^{2}}{4 \beta} \\
= & \frac{\beta^{2}\left(\theta_{i}-c_{i}\right)^{2}+\gamma^{2}\left(\theta_{j}-c_{j}\right)^{2}-2 \gamma \beta\left(\theta_{j}-c_{j}\right)\left(\theta_{i}-c_{i}\right)}{4 \beta\left(\beta^{2}-\gamma^{2}\right)}, \\
& \quad \text { if symmetric: } \quad \Pi_{i}=\frac{(\theta-c)^{2}(\beta-\gamma)}{4 \beta(\beta+\gamma)} .
\end{aligned}
$$

The retailer's profit in the symmetric case is

$$
\begin{aligned}
\pi & =\widehat{\pi}_{i}+\widehat{\pi}_{j}-\widehat{\pi}_{i j} \\
& =\frac{2(\theta-c)^{2}}{4 \beta}-2 \frac{(\theta-c)^{2}}{4(\beta+\gamma)}=\frac{(\theta-c)^{2} \gamma}{2 \beta(\beta+\gamma)} .
\end{aligned}
$$

Consider the equilibrium under quantity-discount and wholesale-price contracts. Based on the demand rates and reaction functions derived in Theorem 1, we can solve the equilibrium for the symmetric problem. Recall that $\delta \equiv$ $(2 \beta-v)^{2}-(2 \gamma)^{2}$. The unique symmetric equilibrium given $v_{i}=v_{j}=v$ is characterized by

$$
\begin{aligned}
w & =\frac{\theta(2 \beta-v-2 \gamma)(\delta+v(2 \beta-v))+c(2 \beta-v) \delta}{\delta(2(2 \beta-v)-2 \gamma)+v(2 \beta-v)(2 \beta-v-2 \gamma)} \\
& =\frac{\theta(\delta+v(2 \beta-v))+c(2 \beta-v)(2 \beta-v+2 \gamma)}{(2 \beta-v+2 \gamma)(2(2 \beta-v)-2 \gamma)+v(2 \beta-v)}, \\
w-c & =\frac{(\theta-c)(2 \beta-v-2 \gamma)(\delta+v(2 \beta-v))}{\delta(2(2 \beta-v)-2 \gamma)+v(2 \beta-v)(2 \beta-v-2 \gamma)} \\
& =\frac{(\theta-c)(\delta+v(2 \beta-v))}{(2 \beta-v+2 \gamma)(2(2 \beta-v)-2 \gamma)+v(2 \beta-v)} .
\end{aligned}
$$

Substituting $v=0$ yields the equilibrium wholesale prices, and taking the limit as $v \rightarrow 2(\beta-\gamma)$ yields the equilibrium under the most aggressive quantity discounts.

$$
\begin{aligned}
& \text { At } v=0 \\
& \begin{aligned}
w=\frac{\theta(\beta-\gamma)+c(\beta)}{(2 \beta-\gamma)}, \quad w-c=\frac{(\theta-c)(\beta-\gamma)}{(2 \beta-\gamma)}, \\
\quad \theta-w=\frac{(\theta-c) \beta}{(2 \beta-\gamma)} . \\
\text { As } v \rightarrow 2(\beta-\gamma), \\
w=\frac{\theta(\beta-\gamma)+c(2 \gamma)}{(\beta+\gamma)}, \quad w-c=\frac{(\theta-c)(\beta-\gamma)}{(\beta+\gamma)}, \\
\theta-w=\frac{(\theta-c)(2 \gamma)}{(\beta+\gamma)} .
\end{aligned}
\end{aligned}
$$

Similarly, the demand rates are given by

$$
\begin{aligned}
d^{*}= & \frac{(2 \beta-v-2 \gamma)(\theta-w)}{(2 \beta-v)^{2}-(2 \gamma)^{2}}=\frac{\theta-w}{2 \beta-v+2 \gamma} \\
= & (\theta(\delta(2(2 \beta-v)-2 \gamma)+v(2 \beta-v)(2 \beta-v-2 \gamma) \\
& \quad-(2 \beta-v-2 \gamma)(\delta+v(2 \beta-v)))-c(2 \beta-v) \delta) \\
& \cdot \frac{1}{2 \beta-v+2 \gamma} \\
= & \frac{(\theta-c) \delta(2 \beta-v)}{\delta(2(2 \beta-v)-2 \gamma)+v(2 \beta-v)(2 \beta-v-2 \gamma)} \frac{1}{2 \beta-v+2 \gamma} \\
= & \frac{(\theta-c)(2 \beta-v-2 \gamma)(2 \beta-v)}{\delta(2(2 \beta-v)-2 \gamma)+v(2 \beta-v)(2 \beta-v-2 \gamma)} \\
= & \frac{(\theta-c)(2 \beta-v)}{(2 \beta-v+2 \gamma)(2(2 \beta-v)-2 \gamma)+v(2 \beta-v)} . \\
& \text { At } v=0, \quad d^{*}=\frac{(\theta-c) \beta}{(2 \beta+2 \gamma)(2 \beta-\gamma)} . \\
p^{*}-w=\theta-(\beta+\gamma) \frac{\theta-w}{2 \beta-v+2 \gamma}-w=\frac{(\theta-w)(\beta-v+\gamma)}{2 \beta-v+2 \gamma} . & \text { As } v \rightarrow 2(\beta-\gamma), \quad d^{*}=\frac{(\theta-c)}{2(\beta+\gamma)} . \\
& \quad(2 \beta-v)
\end{aligned}
$$


The retailer's profit at equilibrium is

$$
\begin{aligned}
& \pi^{*}=2\left(p d-w d+v d^{2} / 2\right)=\frac{2(\theta-w)(\beta-v+\gamma)}{2 \beta-v+2 \gamma} d+v d^{2} \\
& =2 \frac{(\theta-c)^{2}(2 \beta-v+2 \gamma)(2 \beta-v)^{2}}{((2 \beta-v+2 \gamma)(2(2 \beta-v)-2 \gamma)+v(2 \beta-v))^{2}} \frac{(\beta-v+\gamma)}{2 \beta-v+2 \gamma} \\
& +v \frac{(\theta-c)^{2}(2 \beta-v)^{2}}{((2 \beta-v+2 \gamma)(2(2 \beta-v)-2 \gamma)+v(2 \beta-v))^{2}}, \\
& \pi^{*}=\frac{(\theta-c)^{2}(2 \beta-v)^{2}(2 \beta-v+2 \gamma)}{((2 \beta-v+2 \gamma)(2(2 \beta-v)-2 \gamma)+v(2 \beta-v))^{2}} . \\
& \text { At } v=0, \quad \pi^{*}=\frac{(\theta-c)^{2} \beta^{2}}{(2 \beta+2 \gamma)(2 \beta-\gamma)^{2}} \text {. } \\
& \text { As } v \rightarrow 2(\beta-\gamma) \text {, } \\
& \pi^{*}=\frac{2(\theta-w)(\beta-v+\gamma)}{2 \beta-v+2 \gamma}+v d^{2} \\
& =\frac{2((\theta-c)(2 \gamma) /(\beta+\gamma))(\beta-v+\gamma)}{2 \beta-v+2 \gamma} \frac{(\theta-c)}{2(\beta+\gamma)}+v \frac{(\theta-c)^{2}}{4(\beta+\gamma)^{2}} \\
& =\frac{2(2 \gamma)(\beta-v+\gamma)}{2 \beta-v+2 \gamma} \frac{(\theta-c)^{2}}{2(\beta+\gamma)^{2}}+v \frac{(\theta-c)^{2}}{4(\beta+\gamma)^{2}}, \\
& \pi^{*}=\frac{(\theta-c)^{2} \gamma}{(\beta+\gamma)^{2}}
\end{aligned}
$$

The manufacturer's profit at equilibrium is

$$
\begin{aligned}
& \Pi=(w-c) d-v d^{2} / 2=((w-c)-v d / 2) d \\
&=((\theta-c)(2 \beta-v-2 \gamma)(\delta+v(2 \beta-v)) \\
&-(v / 2)(\theta-c)(2 \beta-v-2 \gamma)(2 \beta-v)) \\
& \cdot \frac{(\theta-c)(2 \beta-v-2 \gamma)(2 \beta-v)}{(\delta(2(2 \beta-v)-2 \gamma)+v(2 \beta-v)(2 \beta-v-2 \gamma))^{2}} \\
&= \frac{(\theta-c)^{2}(2 \beta-v-2 \gamma)^{2}(2 \beta-v)(\delta+(v / 2)(2 \beta-v))}{(\delta(2(2 \beta-v)-2 \gamma)+v(2 \beta-v)(2 \beta-v-2 \gamma))^{2}} \\
&=\frac{(\theta-c)^{2}(2 \beta-v)(\delta+(v / 2)(2 \beta-v))}{((2 \beta-v+2 \gamma)(2(2 \beta-v)-2 \gamma)+(1)(2 \beta-v))^{2}} . \\
& \text { At } v=0, \quad \Pi=\frac{((2 \beta+2 \gamma)(2(2 \beta)-2 \gamma))^{2}}{2(\beta+\gamma)(2 \beta-\gamma)^{2}} . \\
& \text { As } v \rightarrow 2(\beta-\gamma), \quad \Pi=\frac{(\theta-c)^{2}(2 \gamma)((\beta-\gamma)(2 \gamma))}{((4 \gamma)(2 \gamma)+2(\beta-\gamma)(2 \gamma))^{2}} \\
&=\frac{(\theta-c)^{2}(\beta-\gamma)}{4(\beta+\gamma)^{2}} . \quad \square
\end{aligned}
$$

THEOREM 8. The incremental profit of the manufacturer in each contract type given the equilibrium contract offer of the other manufacturer is as follows:

$$
I P^{W}=\frac{(\theta-c)^{2}(2 \beta)(\beta-\gamma)}{2(\beta+\gamma)(2 \beta-\gamma)^{2}}, \quad I P^{Q}=I P^{T}=\frac{(\theta-c)^{2}(\beta-\gamma)}{4 \beta(\beta+\gamma)} .
$$

Proof. We know that the two-part tariff extracts the full incremental profit. Hence, $I P^{T}$ is given by the manufacturer's profit at the two-part tariff equilibrium. For the wholesale-price equilibrium, we have $v=0$ and

$$
\theta-w=\frac{(\theta-c) \beta}{(2 \beta-\gamma)}
$$

First, evaluate the retailer's outside option at this contract.

$$
\begin{array}{r}
\pi\left(0, d_{2}(0)\right)=\max \left(p_{2}-w\right) d_{2}=\max \left(\theta-w-\beta d_{2}\right) d_{2}, \\
d_{2}^{*}=\frac{(\theta-w)}{2 \beta}, \quad p_{2}^{*}=\frac{(\theta-w)}{2}, \quad \pi\left(0, d_{2}(0)\right)=\frac{(\theta-c)^{2} \beta}{4(2 \beta-\gamma)^{2}} .
\end{array}
$$

Now, manufacturer 1 offers his product at marginal production cost and manufacturer 2 offers the above wholesaleprice contract.

$$
\begin{gathered}
\max \left(p_{1}-c\right) d_{1}+\left(p_{2}-w\right) d_{2}=\max \left(\theta-c-\beta d_{1}-\gamma d_{2}\right) d_{1} \\
+\left(\theta-w-\beta d_{2}-\gamma d_{1}\right) d_{2} \\
{\left[\begin{array}{l}
d_{1} \\
d_{2}
\end{array}\right]=\frac{\theta-c}{2\left(\beta^{2}-\gamma^{2}\right)}\left[\begin{array}{cc}
\beta & -\gamma \\
-\gamma & \beta
\end{array}\right]\left[\begin{array}{c}
1 \\
\beta /(2 \beta-\gamma)
\end{array}\right],} \\
p_{1}(d)-c=(\theta-c) / 2 \\
p_{2}(d)-w=\frac{(\theta-c) \beta}{2(2 \beta-\gamma)}, \\
\pi\left(d_{1}, d_{2}\right)=\frac{(\theta-c)^{2} \beta}{4\left(\beta^{2}-\gamma^{2}\right)}\left(1-\frac{2 \gamma}{(2 \beta-\gamma)}+\frac{\beta^{2}}{(2 \beta-\gamma)^{2}}\right) .
\end{gathered}
$$

Incremental profit is the retailer's maximum profit minus the outside option.

$$
\begin{aligned}
\pi\left(d_{1},\right. & \left.d_{2}\right)-\pi\left(0, d_{2}(0)\right) \\
= & \frac{(\theta-c)^{2} \beta}{4\left(\beta^{2}-\gamma^{2}\right)}\left(1-\frac{2 \gamma}{(2 \beta-\gamma)}+\frac{\beta^{2}}{(2 \beta-\gamma)^{2}}\right)-\frac{(\theta-c)^{2} \beta}{4(2 \beta-\gamma)^{2}} \\
= & \frac{(\theta-c)^{2} \beta}{4(2 \beta-\gamma)^{2}\left(\beta^{2}-\gamma^{2}\right)} \\
& \cdot\left((2 \beta-\gamma)^{2}-2 \gamma(2 \beta-\gamma)+\beta^{2}-\left(\beta^{2}-\gamma^{2}\right)\right) \\
= & \frac{(\theta-c)^{2} \beta}{4(2 \beta-\gamma)^{2}\left(\beta^{2}-\gamma^{2}\right)}((2 \beta-\gamma)-\gamma)^{2} \\
= & \frac{(\theta-c)^{2}(2 \beta)(\beta-\gamma)}{2(2 \beta-\gamma)^{2}(\beta+\gamma)} .
\end{aligned}
$$

For the quantity-discount equilibrium, we have

$$
v=2(\beta-\gamma), \quad \theta-w=\frac{(\theta-c) 2 \gamma}{(\beta+\gamma)}, \quad d^{*}=\frac{(\theta-c)}{2(\beta+\gamma)} .
$$

The last quantity denotes the equilibrium quantity of each product. It is also the breakpoint of the quantity-discount contract. Let us evaluate the retailer's outside option at this contract. If the retailer offers only product 2 , the order quantity $d_{2}$ will be larger than $d^{*}$, and the marginal cost is equal to $c$ beyond $d^{*}$. Hence,

$$
\begin{gathered}
\pi\left(0, d_{2}(0)\right)=\max p_{2} d_{2}-\left(w d^{*}-(v / 2)\left(d^{*}\right)^{2}+c\left(d_{2}-d^{*}\right)\right), \\
d_{2}^{*}=\frac{(\theta-c)}{2 \beta}, \quad \text { and } \quad p_{2}-c=\frac{(\theta-c)}{2} . \\
\pi\left(0, d_{2}(0)\right)=\frac{(\theta-c)^{2}}{4 \beta}-\left(w d^{*}-(v / 2)\left(d^{*}\right)^{2}-c d^{*}\right) \\
=\frac{(\theta-c)^{2}}{4 \beta}-\frac{(\theta-c)(\beta-\gamma)}{(\beta+\gamma)} \frac{(\theta-c)}{2(\beta+\gamma)} \\
+(\beta-\gamma)\left(\frac{(\theta-c)}{2(\beta+\gamma)}\right)^{2} \\
=\frac{(\theta-c)^{2}}{4 \beta}-\frac{(\theta-c)^{2}(\beta-\gamma)}{4(\beta+\gamma)^{2}} .
\end{gathered}
$$


Now, manufacturer 1 offers his product at marginal production cost, and manufacturer 2 offers the above quantitydiscount contract. Because both marginal costs are $c$, the retailer chooses the system optimal quantities. To verify,

$$
\begin{aligned}
& \max \left(p_{1}-c\right) d_{1}+\left(p_{2}-w\right) d_{2}+v d_{2}^{2} / 2 \\
& \quad=\max \left(\theta-c-\beta d_{1}-\gamma d_{2}\right) d_{1}+\left(\theta-w-\beta d_{2}-\gamma d_{1}\right) d_{2}+v d_{2}^{2} / 2
\end{aligned}
$$

First-order conditions are

$$
\begin{gathered}
0=\left(\theta-c-2 \beta d_{1}-2 \gamma d_{2}\right), \quad 0=\left(\theta-w-2 \gamma d_{2}-2 \gamma d_{1}\right) \\
{\left[\begin{array}{l}
d_{1} \\
d_{2}
\end{array}\right]=\frac{(\theta-c)}{2 \gamma(\beta-\gamma)}\left[\begin{array}{cr}
\gamma & -\gamma \\
-\gamma \beta
\end{array}\right]\left[\begin{array}{c}
1 \\
2 \gamma /(\beta+\gamma)
\end{array}\right]} \\
=\frac{(\theta-c)}{2(\beta-\gamma)}\left[\begin{array}{cc}
1 & -1 \\
-1 & \beta / \gamma
\end{array}\right]\left[\begin{array}{c}
1 \\
2 \gamma /(\beta+\gamma)
\end{array}\right], \\
d_{1}=\frac{(\theta-c)}{2(\beta-\gamma)}\left(1-\frac{2 \gamma}{\beta+\gamma}\right)=\frac{(\theta-c)}{2(\beta+\gamma)^{\prime}} \text { and } \\
d_{2}=\frac{(\theta-c)}{2(\beta-\gamma)}\left(-1+\frac{2 \beta}{\beta+\gamma}\right)=\frac{(\theta-c)}{2(\beta+\gamma)} . \\
\pi\left(d_{1}, d_{2}\right)=\frac{(\theta-c)^{2} \beta(\beta+3 \gamma)}{4(\beta+\gamma)^{2}} .
\end{gathered}
$$

Incremental profit is the retailer's maximum profit minus the outside option.

$$
\begin{aligned}
I P^{Q} & =\pi\left(d_{1}, d_{2}\right)-\pi\left(0, d_{2}(0)\right) \\
& =\frac{(\theta-c)^{2} \beta(\beta+3 \gamma)}{4(\beta+\gamma)^{2}}-\frac{(\theta-c)^{2}}{4 \beta}+\frac{(\theta-c)^{2}(\beta-\gamma)}{4(\beta+\gamma)^{2}} \\
& =\frac{(\theta-c)^{2}}{4 \beta(\beta+\gamma)^{2}}\left(\beta(\beta+3 \gamma)-(\beta+\gamma)^{2}+(\beta-\gamma) \beta\right) \\
& =\frac{(\theta-c)^{2}(\beta-\gamma)}{4 \beta(\beta+\gamma)},
\end{aligned}
$$

which is the same as the incremental profit under two-part tariff.

Theorem 9. Consider the case of symmetric complementary products $(\gamma<0)$ and no economies of scale. The equilibrium under wholesale-price contracts is as given in Table 1 . Under quantity discounts as $v$ goes to $2(\beta+\gamma)$, the equilibrium profit of a manufacturer is $(\theta-c)^{2} / 2(\beta+\gamma)$. Under two-part tariffs, there are multiple equilibria where the manufacturer profits are given by $\left(\widehat{\pi}_{12}-\widehat{\pi}_{2}, \widehat{\pi}_{2}\right)$ or $\left(\widehat{\pi}_{1}, \widehat{\pi}_{12}-\widehat{\pi}_{1}\right)$, or a line segment connecting between them, which also includes the quantity-discount equilibrium. The retailer profit is zero under quantity discounts and two-part tariffs.

Proof. For the quantity-discount contract, substituting $v=2(\beta+\gamma)$ in Equations (18) and (17) gives the profits as stated. For the two-part tariff equilibrium, the equilibrium analysis of Theorem 4 needs to be revisited because with complementary products we have $\widehat{\pi}_{12}>\widehat{\pi}_{1}+\widehat{\pi}_{2}$. For any $\left(F_{1}, c_{1}\right),\left(F_{2}, c_{2}\right)$, we have $\Pi_{i}=F_{i} 1_{\left\{d_{i}^{*}>0\right\}}$, and $\pi=$ $\max \left\{\widehat{\pi}_{1}-F_{1}, \widehat{\pi}_{2}-F_{2}, \widehat{\pi}_{12}-F_{1}-F_{2}, 0\right\}$. Let us focus on the response of manufacturer 1 . If $F_{2} \leq \widehat{\pi}_{2}$, then $\widehat{\pi}_{1}-$ $F_{1} \leq \widehat{\pi}_{12}-F_{1}-F_{2}$ and $\pi=\max \left\{\hat{\pi}_{2}-\bar{F}_{2}, \widehat{\pi}_{12}-F_{1}-F_{2}\right\}$, and manufacturer 1 's best response to $F_{2}$ is to set $F_{1}$ as high as possible while ensuring that $\widehat{\pi}_{12}-F_{1}-F_{2} \geq \widehat{\pi}_{2}-F_{2}$; hence, $F_{1}^{*}\left(F_{2}\right)=\widehat{\pi}_{12}-\widehat{\pi}_{2}$. If $\widehat{\pi}_{12}-\widehat{\pi}_{1} \geq F_{2}=\widehat{\pi}_{2}+\delta$ for $\delta \in\left[0, \widehat{\pi}_{12}-\widehat{\pi}_{1}-\widehat{\pi}_{2}\right]$, then $\pi=\max \left\{\widehat{\pi}_{12}-F_{1}-\right.$ $\left.\widehat{\pi}_{2}-\delta, 0\right\}$, and manufacturer 1 's best response is $F_{1}^{*}=$ $\widehat{\pi}_{12}-F_{2}$. If $F_{2}>\widehat{\pi}_{12}-\widehat{\pi}_{1}$, then $\pi=\max \left\{\widehat{\pi}_{1}-F_{1}, 0\right\}$ and manufacturer 1's best response is $F_{1}^{*}=\hat{\pi}_{1}$. The best response function of manufacturer 2 is similar: $F_{2}^{*}\left(F_{1}\right)=\left\{\widehat{\pi}_{12}-\right.$ $\widehat{\pi}_{1}$ if $F_{1} \leq \widehat{\pi}_{1}, \widehat{\pi}_{12}-F_{1}$ if $\widehat{\pi}_{12}-\widehat{\pi}_{2} \geq F_{2}>\widehat{\pi}_{1}, \widehat{\pi}_{2}$ otherwise $\}$. The equilibrium points are $\left(F_{1}^{*}, F_{2}^{*}\right)=\left(\widehat{\pi}_{12}-\widehat{\pi}_{2}, \widehat{\pi}_{2}\right)$, $\left(\widehat{\pi}_{1}, \widehat{\pi}_{12}-\widehat{\pi}_{1}\right)$, or any linear combination of these two points. The retailer's profit is zero at all equilibria. In the symmetric products case, $\widehat{\pi}_{i}=(\theta-c)^{2} / 4 \beta$ and $\widehat{\pi}_{12}=$ $(\theta-c)^{2} / 2(\beta+\gamma)$, leading to $\left(F_{1}^{*}, F_{2}^{*}\right)=\left((\theta-c)^{2} / 4 \beta,(\theta-c)^{2}\right.$. $(\beta-\gamma) / 4 \beta(\beta+\gamma))$ or the reverse.

\section{References}

Arya, A., B. Mittendorf. 2006. Benefits of channel discord in the sale of durable goods. Marketing Sci. 25(1) 91-96.

Bernheim, B. D., M. D. Whinston. 1985. Common marketing agency as a device for facilitating collusion. RAND J. Econom. 16(2) 269-281.

Bernheim, B. D., M. D. Whinston. 1986. Common agency. Econometrica 54(4) 923-942.

Bernheim, B. D., M. D. Whinston. 1998. Exclusive dealing. J. Political Econom. 106(1) 64-103.

Bernstein, F., A. Federgruen. 2003. Pricing and replenishment strategies in a distribution system with competing retailers. Oper. Res. 51(3) 409-426.

Bernstein, F., A. Federgruen. 2005. Decentralized supply chains with competing retailers under demand uncertainty. Management Sci. 51(1) 18-29.

Besanko, D., M. K. Perry. 1994. Exclusive dealing in a spatial model of retail competition. Internat. J. Indust. Organ. 12(3) 297-329.

Bonanno, G., J. Vickers. 1988. Vertical separation. J. Indust. Econom. 36(3) 257-265.

Buzzell, R. D., J. A. Quelch, W. J. Salmon. 1990. The costly bargain of trade promotion. Harvard Bus. Rev. 68(2) 141-149.

Cachon, G. P. 2003. Supply chain coordination with contracts. A. G. de Kok, S. C. Graves, eds. Handbooks in Operations Research and Management Science: Supply Chain Management, Chap. 6. Elsevier, Amsterdam

Cachon, G. P., M. Lariviere. 2005. Supply chain coordination with revenue sharing: Strengths and limitations. Management Sci. 51(1) 30-44.

Choi, S. C. 1991. Price competition in a channel structure with a common retailer. Marketing Sci. 10(4) 271-296.

Corbett, C., X. de Groote. 2000. A supplier's optimal quantity discount policy under asymmetric information. Management Sci. 46(3) 444-450.

Coughlan, A. 1985. Competition and cooperation in marketing channel choice: Theory and application. Marketing Sci. 4(2) 110-129.

Desai, P., O. Koenigsberg, D. Purohit. 2004. Strategic decentralization and channel coordination. Quant. Marketing Econom. 2(1) $5-22$.

Dun and Bradstreet. 2006. Industry Norms and Key Business Ratios. Dun and Bradstreet Solutions, Bethlehem, PA.

Ingene, C. A., M. E. Perry. 1995. Channel coordination when retailers compete. Marketing Sci. 14(4) 360-377.

Jeuland, A. P., S. M. Shugan. 1983. Managing channel profits. Marketing Sci. 2(3) 239-272.

Kuksov, D., A. Pazgal. 2007. The effects of costs and competition on slotting allowances. Marketing Sci. 26(2) 259-267.

Lee, E., R. Staelin. 1997. Vertical strategic interaction: Implications for channel pricing strategy. Marketing Sci. 16(3) 185-207. 
Martinez de Albeniz, V., G. Roels. 2007. Competing for shelf space. Working paper, University of California, Los Angeles.

Marx, L., G. Shaffer. 2010. Slotting allowances and scarce shelf space. J. Econom. Management Strategy. Forthcoming.

Mathewson, G. F., R. A. Winter. 1987. The competitive effects of vertical agreements: Comment. Amer. Econom. Rev. 77 1057-1062.

McGuire, T. W., R. Staelin. 1983. An industry equilibrium analysis of downstream vertical integration. Marketing Sci. 2(2) 161-191.

Monahan, J. P. 1984. A quantity discount pricing model to increase vendor profits. Management Sci. 30(6) 720-726.

Moorthy, K. S. 1987. Managing channel profits: Comment. Marketing Sci. 6(4) 375-379.

Moorthy, K. S. 1988. Strategic decentralization in channels. Marketing Sci. 7(4) 335-355.
Munson, C. L., M. J. Rosenblatt. 1998. Theories and realities of quantity discounts: An exploratory study. Production Oper. Management 7(4) 352-369.

O'Brien, D., G. Shaffer. 1993. On the dampening-of-competition effect of exclusive dealing. I. Indust. Econom. 41(2) 215-221.

O'Brien, D., G. Shaffer. 1997. Nonlinear supply contracts, exclusive dealing, and equilibrium market foreclosure. J. Econom. Management Strategy 6(4) 755-785.

Rey, P., J. Stiglitz. 1995. The role of exclusive territories in producers' competition. RAND J. Econom. 26(3) 432-451.

Tellis, G. J. 1988. The price sensitivity of competitive demand: A meta analysis of sales response models. J. Marketing Res. 15(3) 331-341.

Trivedi, M. 1998. Distribution channels: An extension of exclusive retailership. Management Sci. 44(7) 896-909. 